\title{
Ordenación de las actividades económicas tras las sentencias del Tribunal Constitucional sobre la Ley de Unidad de Mercado
}

\section{Regulation of economic activities following the Constitutional Court's judgments on the Law of Market Unity}

\author{
Javier Sola Teyssiere \\ Universidad de Sevilla (España) \\ ORCID: https://orcid.org/0000-0003-3184-5535 \\ jsola@us.es
}

\section{NOTA BIOGRÁFICA}

Catedrático E. U. de Derecho Administrativo en la Universidad de Sevilla. Doctor en Derecho por la Universidad de Sevilla. Principales líneas de investigación: Derecho del turismo, ordenación territorial de los espacios turísticos, unidad de mercado, Derecho Administrativo económico.

\section{RESUMEN}

El Tribunal Constitucional, a través de varias Sentencias dictadas en 2017, ha declarado la inconstitucionalidad de los artículos de la Ley de Garantía de la Unidad de Mercado reguladores del principio de eficacia en todo el territorio nacional de los medios de intervención administrativa sobre el acceso a las actividades económicas, así como otros preceptos por su conexión con el mismo. En la primera parte del trabajo se examinan los motivos de inconstitucionalidad alegados por el Tribunal y se hace una valoración del impacto y alcance fáctico que conlleva dicha anulación. En segundo lugar, se estudia el sistema de ordenación de las actividades económicas dispuesto en la mencionada Ley, -que en su mayor parte, por el contrario, ha sido avalado por el TC-, abordando la explicación del esquema de instrumentos de intervención de las actividades y sus límites, el ámbito de disposición de requisitos o condiciones materiales ligados al ejercicio de las mismas, finalizando con el examen de ciertas actuaciones específicas que la propia Ley califica como limitaciones no admitidas.

\section{PALABRAS CLAVE}

Unidad de mercado; principio de eficacia nacional; principio de necesidad y proporcionalidad; desregulación.

\begin{abstract}
The Constitutional Court, through several judgments issued in 2017, has declared the unconstitutionality of the articles of the Law on Market Unity Guarantee regulating the principle of effectiveness throughout the national territory of the means of administrative intervention on access to economic activities, as well as other precepts for their connection to it. In the first part of the paper, the grounds for unconstitutionality alleged by the Court are examined and an assessment is made of the impact and factual significance of such annulment. Secondly, we study the system for the ordination of economic activities set forth in the aforementioned Law, -which for the most part, on the contrary, has been endorsed by the TC-, addressing the explanation of the scheme of intervention instruments of the activities and their limits, the scope of disposition of requirements or material conditions linked to the exercise of same, ending with the examination of certain specific actions that the Law itself qualifies as limitations not admitted.
\end{abstract}

\section{KEYWORDS}

Market unity; national effectiveness principle; necessity and proportionality principle; deregulation. 
REALA. Nueva Época - N. ${ }^{0}$ 11, Abril-Septiembre 2019 - ISSN: 1989-8975 - DOI: 10.24965/reala.v0i11.10632 - [Págs. 29-55]

Ordenación de las actividades económicas tras las sentencias del Tribunal Constitucional sobre la Ley de Unidad de Mercado

Javier Sola Teyssiere

\begin{abstract}
SUMARIO
I. LA LEY DE GARANTÍA DE LA UNIDAD DE MERCADO EN EL CONTEXTO DE UN PROCESO DESREGULADOR. II. SITUACIÓN TRAS LAS SSTC DE 2017 SOBRE LA LGUM: 1. INCONSTITUCIONALIDAD DE LA ACTUAL FORMULACIÓN DEL PRINCIPIO DE EFICACIA NACIONAL. A) Los motivos de inconstitucionalidad. B) Acotación del alcance de la anulación del principio de eficacia. 2. EL AVAL DEL TC AL SISTEMA DE LIMITACIÓN DE LOS MEDIOS DE INTERVENCIÓN ADMINISTRATIVA SOBRE LAS ACTIVIDADES ECONÓMICAS. 3. LA MALOGRADA LEY DE GARANTÍA DE LA UNIDAD DE MERCADO NO GARANTIZA LA UNIDAD DE MERCADO, PERO SÍ MANTIENE SU CARÁCTER DESREGULADOR. III. EL ESQUEMA DE MEDIOS Y LÍMITES DE ORDENACIÓN: 1. EN RELACIÓN CON EL INSTRUMENTO DE INTERVENCIÓN. A) Autorizaciones. B) Declaraciones responsables. C) Comunicaciones. 2. LA DISPOSICIÓN DE CONDICIONES MATERIALES RELATIVAS AL EJERCICIO DE LAACTIVIDAD. 3. ACTUACIONES CALIFICADAS COMO LIMITACIONES NO ADMITIDAS. IV. EXTRACTO Y CONCLUSIONES.
\end{abstract}

\title{
I. LA LEY DE GARANTÍA DE LA UNIDAD DE MERCADO EN EL CONTEXTO DE UN PROCESO DESREGULADOR
}

La Ley 20/2013, de 9 de diciembre, de Garantía de la Unidad de Mercado (LGUM) constituye el último episodio de un proceso desregulador del ejercicio de las actividades económicas cuyo germen cercano puede conectarse con la Directiva 2006/123/CE del Parlamento Europeo y del Consejo, de 12 de diciembre, relativa a los servicios en el mercado interior. Efectivamente, resulta perceptible que la Directiva de Servicios, junto al objetivo declarado de impulso a la integración del mercado único, incorpora igualmente un propósito genérico de liberalización de la actividad económica y más específico de simplificación de cargas administrativas para las empresas del sector servicios. No empece a la conexión aludida el hecho de que la LGUM no presente un vínculo formal con la normativa europea. Significativamente, el preámbulo de la LGUM declara haber tenido en cuenta los principios pertinentes derivados de la jurisprudencia del TJUE (que son los que han «nutrido» el contenido de la Directiva de Servicios), así como la experiencia adquirida con la transposición de la Directiva de Servicios. Por otra parte la LGUM se encuadra en la estrategia económica europea de crecimiento y no es ajena a las reiteradas recomendaciones del Consejo Europeo a nuestro país de eliminar obstáculos al ejercicio de actividades económicas ${ }^{1}$.

A nivel interno, es realmente en la normativa de transposición de la mencionada Directiva donde hay que situar los antecedentes directos de la LGUM. Como es sabido, el núcleo de la ingente normativa, a todos los niveles, que hubo que dictar para la transposición de la Directiva de Servicios en nuestro país tuvo como foco principal la remoción de restricciones a la libertad de establecimiento y a la libre prestación de los servicios incluidos en su ámbito de aplicación. En este proceso, resultan especialmente significativas las modificaciones llevadas a cabo en dos leyes generales, como la antigua Ley 30/1992, de Régimen Jurídico de las Administraciones Públicas y del Procedimiento Administrativo Común y en la Ley $7 / 1985$, Reguladora de las Bases del Régimen Local, por parte de la llamada Ley Omnibus², introduciendo tanto los nuevos principios de intervención administrativa sobre actividades como la regulación genérica de los entonces novedosos instrumentos de declaración responsable y comunicaciones previas.

Especialmente visible es la trabazón de la LGUM con la Ley 17/2009, de 23 de noviembre, sobre el libre acceso a las actividades de servicios y su ejercicio (Ley Paraguas), con la que mantiene evidentes puntos de conexión. De hecho en la Ley Paraguas ya está presente el esquema básico de simplificación de procedimientos y de limitación de las posibilidades de intervención administrativa sobre el acceso a las actividades de servicios que, más tarde, la LGUM endurece y amplia al resto de actividades económicas.

La Ley 2/2011, de 4 de marzo, de Economía Sostenible, insistió en la dirección liberalizadora apuntada reafirmando los principios de necesidad, proporcionalidad y simplicidad de las iniciativas normativas, pro-

1 Vid. en este sentido J. SOLA TEYSSIERE, "Unidad de mercado y supervisión administrativa de las actividades económicas", Revista de Administración Pública, núm. 197, 2015, págs. 134-135, así como la documentación allí citada. La influencia de la Unión Europea alentando la aprobación y aplicación de la LGUM es explicada de manera más detallada y actualizada por J. SOLANES MULLOR, "La desconstitucionalización y europeización del principio de unidad de mercado: el Estado de las Autonomías bajo presión", Revista Vasca de Administración Pública, núm. 109-II, 2017, págs. 99-102.

${ }^{2}$ Ley 25/2009, de 22 de diciembre, de modificación de diversas leyes para su adaptación a la Ley sobre el libre acceso a las actividades de servicios y su ejercicio que, a través de su artículo primero, introdujo nuevos artículos 39 bis y 71 bis en la antigua Ley 30/1992 y modificó el artículo 84 de la LBRL. 
curando el mantenimiento de un marco normativo «sin más cargas administrativas para los ciudadanos y empresas que las estrictamente necesarias para la satisfacción del interés general» (art. 4).

A finales de 2013, la aprobación de la LGUM supone la implantación de una mayor limitación de las posibilidades de intervención administrativa sobre el acceso a las actividades, además de ampliar dicho esquema regulador a las actividades económicas en general, como se verá más detenidamente. Es por ello, que la LGUM se ve obligada a modificar aspectos sustanciales de la Ley Paraguas, para ajustarla a las nuevas restricciones introducidas por la primera y así homogeneizar el sistema ${ }^{3}$. Por las mismas fechas, la Ley 27/2013, de 27 de diciembre, de Racionalización y Sostenibilidad de la Administración Local, modifica la redacción del artículo 84 bis de la Ley de Bases de Régimen Local con el mismo propósito normalizador.

Con esta sucinta relación de hitos legislativos se ha querido poner de manifiesto que la LGUM no debe ser considerada como una ley inaugural de un esquema nuevo de intervención administrativa económica, sino que forma parte de un proceso, de una estrategia liberalizadora continuada en el tiempo, de la que dicha Ley supone el último episodio significativo.

No obstante, sí es cierto que la LGUM ha supuesto un salto cuantitativo y cualitativo en el aludido proceso desregulador.

Cuantitativamente porque, sobrepasando el perímetro de actividades afectadas por la normativa de transposición de la Directiva de Servicios, amplía su ámbito de aplicación «al acceso a actividades económicas en condiciones de mercado y su ejercicio por parte de operadores legalmente establecidos en cualquier lugar del territorio nacional» (art. 2); lo que puede leerse como actividades económicas en general, salvo contadas excepciones ${ }^{4}$.

Cualitativamente, porque introduce una severa limitación a la hora de regular los medios de intervención pública sobre las actividades económicas, que afecta especialmente a los poderes autonómicos ${ }^{5} \mathrm{y}$ locales. En concreto, restringe los posibles motivos justificativos del establecimiento de autorizaciones, declaraciones responsables y comunicaciones a unas concretas razones imperiosas de interés general, especialmente constreñidas en el caso de que la medida de intervención a utilizar sea una autorización.

Además establece limitaciones en relación con los criterios y requisitos que las Administraciones pueden introducir en las prescripciones y pliegos de sus contratos y en las bases reguladoras de sus actuaciones de fomento; con lo cual está ampliando también en este aspecto su ámbito de aplicación material, que no se limita a la ordenación del acceso y ejercicio de las actividades económicas como esta ha sido tradicionalmente entendida.

La Ley de Garantía de la Unidad de Mercado aunque, aparentemente, atendiendo a su título y a las declaraciones de su preámbulo, tiene como objetivo el restablecimiento de una unidad de mercado que el legislador considera fragmentada, en realidad lo desborda, incluyendo también medidas directamente dirigidas hacia la reducción regulatoria y de cargas administrativas. El propio preámbulo lo reconoce abiertamente cuando declara que la Ley «aprovecha para seguir impulsando un marco regulatorio eficiente para las actividades económicas que simplifique la legislación existente, elimine regulaciones innecesarias, establezca procedimientos más ágiles y minimice las cargas administrativas».

Es por ello que el sistema dispuesto por la LGUM, sucintamente descrito, gravita sobre dos aspectos sustantivos, que constituyen sus ejes centrales, más otros elementos de carácter instrumental dirigidos a apuntalarlos.

El primero de dichos aspectos es sin duda el principio de intervención mínima ${ }^{6}$, encarnado en la Ley por el principio de necesidad y proporcionalidad de las actuaciones de las autoridades competentes ${ }^{7}$ que supon-

\footnotetext{
3 Modificación llevada a cabo a través de su Disposición final segunda.

4 A sensu contrario, aquellas actividades económicas que no se desarrollen en condiciones de mercado, como «la puesta en el mercado de los productos estancos, explosivos, gasóleo profesional y mercancías peligrosas» prevista en la Disposición adicional segunda de la propia LGUM, que deberán respetar los requisitos establecidos en la normativa estatal aplicable a los mismos.

5 Para M. REBOLLO PUIG, dado que el legislador estatal podrá seguir imponiendo límites a la libertad de empresa a través de leyes posteriores, «la novedad y la cuestión crucial están, pues, en el límite que el artículo 5 LGUM impone a los Parlamentos autonómicos», por lo que considera que la LGUM «es sólo una garantía de la libertad de empresa frente a las leyes autonómicas»; "La libertad de empresa tras la Ley de Garantía de la Unidad de Mercado", Revista Española de Derecho Administrativo, núm. 163,2014, pág. 32.

6 Así, LEÓN SANZ, J., "La garantía de la unidad de mercado", Rev. Información Comercial Española, núm. 871, 2013, págs. 40-41.

7 Conforme a lo previsto en el Anexo de definiciones, para la LGUM, autoridad competente es «cualquier organismo o entidad que lleve a cabo la regulación, ordenación o control de las actividades económicas, o cuya actuación afecte al acceso a una actividad económica o a su ejercicio y, en particular, las autoridades administrativas estatales, autonómicas o locales y los colegios profesionales y, en su caso, consejos generales y autonómicos de colegios profesionales».
} 
gan límites a la libertad de empresa, enunciado en su artículo 5, que tiene su instrumentación en positivo (requisitos de las actuaciones) y en negativo (actuaciones prohibidas) en los artículos 17 y 18, respectivamente.

El segundo elemento nuclear de la LGUM era -en pasado, pues ha sido desactivado por el TC, como comentaremos más adelante- la regulación del principio de eficacia, conforme al cual se reconocía efecto en todo el territorio nacional a las actuaciones administrativas de control de acceso a las actividades económicas. Según el anulado artículo 19 de la Ley, cualquier operador que hubiera accedido legalmente a su actividad cumpliendo los requisitos dispuestos en su lugar de origen podría ejercer su actividad en todo el territorio nacional, debiendo las autoridades de destino asumir la plena validez de dichos requisitos aunque difirieran de los propios.

La Ley así, en primer lugar, cercena por abajo las posibilidades regulatorias autonómicas y locales para disponer requisitos de acceso a las actividades económicas, reduciéndolas a un estrecho margen. Las CCAA y las entidades locales sólo podrán establecer requisitos al acceso del operador dentro de ese margen. En segundo lugar, la entrada en juego del principio de eficacia reforzaba la operación desreguladora, en tanto se pronosticaba que propiciaría la opción más liberal para atraer empresas y también probablemente atendiendo a presiones del empresariado local no dispuesto a sufrir la competencia de otros empresarios que soportaran menores cargas.

Junto a los dos elementos destacados, la LGUM despliega un conjunto de instrumentos que parecen responder más propiamente a sus objetivos declarados.

En primer lugar, contiene medidas encaminadas a evitar la dispersión del sistema normativo en el ámbito económico basadas en la cooperación. Bien ex ante, con carácter preventivo, mediante un sistema de información y valoración previa de la normativa con potencial incidencia en la unidad de mercado (art. 14). Bien a posteriori, a través de la evaluación periódica del impacto de la normativa sobre la unidad de mercado en el seno de las Conferencias Sectoriales (art. 15).

En segundo lugar, se ocupa del aparato organizativo, nuevo (Consejo para la Unidad de Mercado) o preexistente (Conferencias Sectoriales), de apoyo a la implantación de la Ley

Por otra parte, como correlato a la regulación del principio de eficacia nacional, establece reglas relativas a la ejecución de la supervisión administrativa en el momento de acceso y sobre el posterior ejercicio de las actividades económicas; aspecto que también ha resultado «tocado» por el TC, como se verá en el siguiente apartado.

Por último, instaura mecanismos que podríamos calificar de garantía o reparación, como el recurso administrativo contra actos incompatibles con las libertades de establecimiento o circulación (artículo 26), el procedimiento de información de obstáculos a la unidad de mercado (artículo 28) y el recurso contenciosoadministrativo para la garantía de la unidad de mercado introducido por la disposición final primera ${ }^{9}$, igualmente afectado en un aspecto relevante por sentencia del TC.

\section{SITUACIÓN TRAS LAS SSTC DE 2017 SOBRE LA LGUM}

Con fecha 8 de abril de 2014, el Pleno del Tribunal Constitucional admite a trámite tres recursos de inconstitucionalidad contra diversos preceptos de la LGUM promovidos, respectivamente, por el Parlamento de Cataluña ${ }^{10}$,

\footnotetext{
${ }^{8}$ Sobre el tema puede verse OCHOA MONZÓ, J., "El entramado institucional de la LGUM", en ob. col. El nuevo marco jurídico de la unidad de mercado. Comentario a la Ley de garantía de la unidad de mercado, dir. M. J. Alonso Mas, Madrid, 2014, págs. 391-400.

${ }^{9}$ Sobre los tres mecanismos anteriores pueden verse, respectivamente, los trabajos de CASARES MARCOS, A., "Mecanismos de protección de los operadores económicos en el ámbito de la libertad de establecimiento y de la libertad de circulación: procedimiento en defensa de los derechos e intereses de los operadores económicos por las autoridades competentes (artículo 26)", BUISÁN GARCÍA, N., "Otros mecanismos de protección de la unidad de mercado", y SANTAMARÍA PASTOR, A., "El contencioso de la unidad de mercado", todos ellos en la ob. col. El nuevo marco jurídico de la unidad de mercado, dir. M. J. Alonso Mas, cit.; y el trabajo de SANTAMARÍA, bajo el mismo título, también en Revista Andaluza de Administración Pública, núm. 87, 2013, págs. 51-93. Sobre los aludidos mecanismos también pueden verse PADRÓS REIG, C. y MACÍAS CASTAÑO, J. M., "Los instrumentos administrativos de garantía de la unidad de mercado", Revista de Administración Pública, núm. 194, 2014, págs. 113-151; y CARLÓN RUIZ, M., "Los mecanismos de protección de la unidad de mercado en el seno de la Ley 20/2013", Revista Española de Derecho Administrativo, núm. 165, 2014, págs. 147-182.

10 Providencia de 8 de abril de 2014, admitiendo a trámite el recurso de inconstitucionalidad numerado 1397-2014 (BOE de 15 de abril), contra distintos preceptos de la LGUM, entre otros, el apartado segundo del artículo 14, y por conexión el apartado segundo del artículo 23; los artículos 16, 17 y 18, y por conexión el artículo 5 y la disposición final segunda; los artículos 19 y 20 y por conexión la disposición adicional décima, y asimismo, el apartado quinto del artículo 26; el artículo 27, en relación con la disposición final primera
} 
REALA. Nueva Época - N. ${ }^{0}$ 11, Abril-Septiembre 2019 - ISSN: 1989-8975 - DOI: 10.24965/reala.v0i11.10632 - [Págs. 29-55]

Ordenación de las actividades económicas tras las sentencias del Tribunal Constitucional sobre la Ley de Unidad de Mercado

Javier Sola Teyssiere

por el Gobierno de Cataluña ${ }^{11}$ y por el Consejo de Gobierno de Andalucía ${ }^{12}$. Posteriormente, en septiembre del mismo año, admite a trámite un nuevo recurso presentado por el Gobierno de Canarias dirigido, igualmente, contra algunos preceptos de la LGUM ${ }^{13}$

Estos cuatro recursos han sido resueltos por sendas Sentencias, dictadas todas a lo largo de 2017, cuyo interés no solo radica en las declaraciones de inconstitucionalidad de varios artículos clave en la arquitectura de la LGUM sino, igualmente, en la confirmación de constitucionalidad de otros -cuya funcionalidad se mantiene a pesar de la anulación de los anteriores- que ha resultado transcendental para que no se haya frustrado enteramente la operación desreguladora descrita en el apartado anterior. Examinaremos sucesivamente estos dos aspectos, a través del comentario de las Sentencias que se irán citando a continuación.

\section{Inconstitucionalidad de la actual formulación del principio de eficacia nacional}

\section{A) Los motivos de inconstitucionalidad}

La Sentencia del Tribunal Constitucional 79/2017, de 22 de junio de 2017, resuelve el recurso interpuesto por el Parlamento de Cataluña, declarando la inconstitucionalidad de los artículos 19 y 20 y, por conexión, de las letras b), c) y e) del apartado 2 del artículo 18 y de la disposición adicional décima de la LGUM ${ }^{14}$, que son los que establecen detalladamente la regulación del principio de eficacia en todo el territorio nacional de las actuaciones administrativas de control de acceso a las actividades económicas. Posteriormente, la STC 110/2017, de 5 de octubre, que resuelve el recurso planteado por el Gobierno de Cataluña, declaró la inconstitucionalidad del artículo 6, que enuncia el aludido principio. Por su parte, la STC 111/2017, de 5 de octubre, al resolver el recurso del Consejo de Gobierno de Andalucía, declara la inconstitucionalidad del apartado c) del artículo 21.2, que también está vinculado al aludido principio de eficacia en cuanto, como instrumento aplicativo derivado del mismo, establecía la regla de que la autoridad del lugar de fabricación era la competente «para el control del cumplimiento de la normativa relacionada con la producción y los requisitos del producto para su uso y consumo», cuya validez debía, por tanto, ser asumida por la autoridad de destino ${ }^{15}$.

Con todo ello, queda seriamente afectado el sistema de reconocimiento de eficacia de las actuaciones de las autoridades competentes en todo el territorio nacional, que fue valorado en su momento como uno de los aspectos más novedosos de la LGUM $^{16}$.

Muy resumidamente recordaremos que, conforme a dicho sistema, cualquier operador económico que hubiera accedido legalmente a su actividad cumpliendo los requisitos dispuestos en su lugar de origen quedaba habilitado para ejercer dicha actividad en todo el territorio nacional, debiendo las autoridades de

que añade los apartados primero y segundo del artículo 127 quater de la Ley 29/1998, de 13 de julio, reguladora de la jurisdicción contenciosa administrativa; y la disposición final cuarta.

11 Recurso 1411-2014, contra los artículos 5, 6, 14.2, 16 a 20, 23, 26.5, 27, disposición adicional décima y disposiciones finales primera, segunda, tercera y cuarta.

12 Recurso 1454-2014, contra los artículos 6; 14.2; 17, último inciso del párrafo primero y letras a) a d); 18.2, letras b) a f); 19; 20 ; 21.2 y $3 ; 23.2 ; 26 ; 27$; disposición adicional décima y disposiciones finales primera, segunda y cuarta.

13 Providencia de 29 de septiembre de 2014, admitiendo a trámite el recurso de inconstitucionalidad numerado 5437-2014, contra los artículos 6,19 y 20.

14 La Sentencia también declara la inconstitucionalidad del apartado segundo del artículo 127 quater de la Ley 29/1998, de 13 de julio, reguladora de la jurisdicción contencioso-administrativa, en la redacción dada por el punto tres de la disposición final primera de la LGUM, únicamente en su aplicación a actos o disposiciones de las Comunidades Autónomas. Por otra parte declara que el inciso «que deberá ser tenido en cuenta por la autoridad competente a la hora de decidir» del último párrafo del artículo 26.5 b) de la LGUM, es conforme con la Constitución interpretado en los términos señalados en el fundamento jurídico 15 . Finalmente, desestima el recurso respecto al resto de preceptos recurridos: apartado segundo del artículo 14, y por conexión el apartado segundo del artículo 23; los artículos 16, 17 y 18, y por conexión el artículo 5 y la disposición final segunda (cuyo comentario se aborda en el siguiente apartado en el texto); el apartado quinto del artículo 26; el apartado primero y, por conexión, el apartado segundo de la disposición final tercera que dan una nueva redacción al artículo 2 y a la disposición final décima de la Ley 12/2012, de 26 de diciembre, de medidas urgentes de liberalización del comercio y de determinados servicios; y la disposición final cuarta. Vid. un comentario in extenso de esta Sentencia en J. SOLA TEYSSIERE, "La existencia de un estándar normativo equivalente como condición de constitucionalidad del anulado principio de eficacia nacional de la Ley de Unidad de Mercado (STC 79/2017)", Revista Española de Derecho Administrativo, núm. 189, 2018, págs. 173-199.

${ }^{15}$ La cuarta y última Sentencia 119/2017, de 31 de octubre, que resuelve el recurso de inconstitucionalidad presentado por el Gobierno de Canarias contra los artículos 6, 19 y 20, declara extinguida la impugnación por pérdida sobrevenida de su objeto.

16 Resaltaron la novedad del principio, entre otros, G. FERNÁNDEZ FARRERES, "Unidad de mercado y libertades de empresa y de circulación en la Ley 20/2013, de 9 de diciembre”, Revista Española de Derecho Administrativo, núm. 163, 2014, pág. 138; J. TORNOS MAS, cit., pág. 165; y M. CARLÓN RUIZ, cit., pág. 151. También destacó su carácter novedoso el Consell de Garanties Estatutàries de Cataluña, en su Dictamen 5/2014, de 14 de febrero, sobre la LGUM, para el que dicho principio constituye la principal novedad que la Ley aporta al ordenamiento jurídico «y sin duda se convierte en su elemento basilar» (FJ Segundo, 4, C). 
REALA. Nueva Época - N. ${ }^{0}$ 11, Abril-Septiembre 2019 - ISSN: 1989-8975 - DOI: 10.24965/reala.v0i11.10632 - [Págs. 29-55]

Ordenación de las actividades económicas tras las sentencias del Tribunal Constitucional sobre la Ley de Unidad de Mercado

Javier Sola Teyssiere

destino ${ }^{17}$ asumir la plena validez de dichos requisitos aunque difirieran de los propios. Se reconocía así efecto en todo el territorio nacional a las actuaciones administrativas de control de acceso de las actividades económicas en general, en consonancia con el ámbito de aplicación de la LGUM. La regla incluía a los bienes y productos, de forma que cualquiera producido cumpliendo los requisitos del lugar de origen podría circular y ofertarse libremente en todo el territorio español, debiendo las autoridades de los territorios donde fueran comercializados asumir como válidos dichos requisitos aunque fueran diferentes que los establecidos en sus propios territorios.

Partiendo de estos postulados, el artículo 20 recogió una relación detallada de posibles medios de intervención admitiendo expresamente su plena eficacia en todo el territorio nacional (autorizaciones, licencias, habilitaciones, cualificaciones profesionales, declaraciones responsables, comunicaciones, inscripciones en registros, acreditaciones o certificaciones emitidas por organismos de evaluación, etcétera). El sistema se completaba con la prohibición general a las autoridades de destino de exigir a los operadores ya habilitados el cumplimiento de nuevos requisitos o trámites adicionales para operar en sus territorios (art. 20.1, primer párrafo in fine), reforzada por la calificación como contraria a la Ley del eventual establecimiento por parte de las autoridades de destino de requisitos (acreditaciones, calificaciones, certificaciones, seguros, fianzas, especificaciones técnicas, etc.), distintos o adicionales a los requeridos en origen al operador, para poder ejercer la actividad en sus territorios (art. 18.2).

En definitiva, con ello la LGUM determinaba el régimen de las actuaciones administrativas de control inicial de acceso a las actividades económicas en general, conforme al cual, si el operador cumplía los requisitos establecidos en un determinado territorio para acceder al ejercicio de su actividad, adquiría un título habilitante eficaz en todo el territorio nacional, sin que las autoridades del resto de territorios pudieran exigirle nuevos requisitos para operar en los mismos. De esta manera, la aplicación de los medios de intervención dispuestos en estos últimos territorios para controlar el acceso al ejercicio de esa misma actividad quedaba, por así decirlo, desactivada.

La regulación del principio de eficacia ya se había revelado como uno de los aspectos más polémicos de la LGUM, contra el que se dirigieron los cuatro recursos de inconstitucionalidad interpuestos frente a la misma, y ante la que se habían posicionado muy críticamente diversos órganos consultivos, ya durante la tramitación de la Ley ${ }^{18}$ y después de su aprobación ${ }^{19}$, así como una cualificada doctrina ${ }^{20}$. Tanto las críticas como la fundamentación de los recursos se sustentaban básicamente en dos motivos. Por un lado, el cercenamiento de las competencias autonómicas en relación con las actividades económicas y, por otro, la contravención del principio de territorialidad de dichas competencias. Ambas alegaciones son acogidas en la STC 79/2017, en los términos que muy sucintamente se examinan a continuación.

Respecto a la primera el Tribunal, partiendo de la consideración de que los preceptos impugnados han sido dictados al amparo del artículo 149.1.13 CE, entiende que lo que se plantea en el proceso es si la regulación del principio de eficacia nacional establecida por la LGUM constituye un ejercicio legítimo de dicho instrumento conectado con la ordenación general de la economía. Para el análisis de dicha cuestión, parte del contraste de lo establecido por la LGUM respecto a una técnica previamente experimentada en el derecho comunitario europeo con la misma finalidad de atenuar los efectos disfuncionales derivados de la diversidad regulatoria de los distintos Estados miembros de la UE: el principio de reconocimiento mutuo de actuaciones entre dichos Estados ${ }^{21}$. La aplicación de la técnica de reconocimiento mutuo exige, no obstante,

17 El artículo 21.2 LGUM determina a qué autoridad corresponden las funciones ejecutivas de supervisión sobre las actividades económicas, conforme al siguiente esquema: a) a la autoridad de origen la supervisión de los requisitos de acceso; b) a la de destino la supervisión del ejercicio de la actividad; c) a la del lugar de fabricación el control de los requisitos de producción y del producto para su uso y consumo (esta última regla ahora anulada por el TC, como se ha dicho).

18 Cfr. el Informe del Consejo General del Poder Judicial sobre el anteproyecto de la LGUM, de 11 de abril de 2013, págs. 21-24 y el Dictamen del Consejo Económico y Social, de 18 de abril de 2013, págs. 8-9 y 14.

19 Aprobada ya la LGUM, sus artículos 19 y 20 son considerados inconstitucionales tanto en el Dictamen 5/2014, de 14 de febrero, del Consell de Garanties Estatutàries de Cataluña como en el Dictamen 193/2014, de 19 de marzo, del Consejo Consultivo de Andalucía.

20 Vid., especialmente, G. FERNÁNDEZ FARRERES, cit., págs. 133-142 y J. TORNOS MAS, cit., págs. 163-168; autores ambos que denunciaron la inconstitucionalidad de la regulación de dicho principio (pág. 139 y pág. 167, respectivamente). En la misma línea, I. URRUTIA LIBARONA consideró que la configuración legal del principio resultaba de dudosa constitucionalidad; "La configuración legal de la unidad de mercado y Estado autonómico", Revista Española de Derecho Administrativo, núm. 175, 2016, pág. 235. También se mostró crítico S. MUÑOZ MACHADO, "Sobre el restablecimiento legal de la unidad de mercado", Revista Española de Derecho Administrativo, núm. 163, 2014, pág. 19.

21 La doctrina sobre la aplicación del principio de reconocimiento mutuo en el mercado interior se ha venido elaborando por el TJUE a partir de la conocida Sentencia Cassis de Dijon, de 20 de febrero de 1979 y posteriormente aparece expresa y repetidamente 
REALA. Nueva Época - N. ${ }^{0}$ 11, Abril-Septiembre 2019 - ISSN: 1989-8975 - DOI: 10.24965/reala.v0i11.10632 - [Págs. 29-55]

Ordenación de las actividades económicas tras las sentencias del Tribunal Constitucional sobre la Ley de Unidad de Mercado

Javier Sola Teyssiere

como presupuesto, la equivalencia en el nivel de protección en el país de origen y el de destino, conforme a la doctrina establecida por el Tribunal de Justicia de la Unión Europea.

Extrapolando esta doctrina al derecho interno el TC considera que «en la medida en que exista una normativa de la Unión Europea armonizada o una legislación estatal común, o exista una pluralidad de legislaciones autonómicas que, no obstante sus posibles diferencias técnicas o metodológicas, fijen un estándar que pueda ser considerado equivalente, el Estado podrá reconocer a las decisiones autonómicas efectos extraterritoriales a través de la imposición del reconocimiento de la decisión adoptada en una determinada Comunidad Autónoma en el resto». Ahora bien, caso de no darse esta circunstancia, quedaría "subsistente la capacidad de los poderes territoriales de poder establecer [..] un nivel de protección propio y distinto» (FJ 12).

Por otra parte, apunta el TC, el poder central puede intervenir, a fin de mitigar las consecuencias derivadas de la pluralidad regulatoria, a través de una estrategia de armonización del marco normativo de aplicación, de tal manera que se produjera una equivalencia de régimen jurídico ante las mismas situaciones. Ello supondría el establecimiento de «un común denominador normativo dirigido a asegurar aquellos rasgos que caracterizan la unidad de mercado y entre los que se encuentra ser un espacio donde las condiciones esenciales de ejercicio de la actividad económica sean iguales», a través del ejercicio por parte del Estado de sus competencias horizontales, vía artículo 149.1.13 CE.

Sin embargo, el sistema empleado por la LGUM ni sigue la técnica del reconocimiento mutuo ni establece un marco normativo armonizado.

No sigue el principio de reconocimiento mutuo por no haber dispuesto simultáneamente, como condición de su aplicación, la existencia de una equivalencia en el nivel de protección de las distintas normativas territoriales. Según el TC ${ }^{22}$, este extremo está «ausente en la regulación del principio de eficacia nacional recogido en la Ley 20/2013 en el que la autoridad de destino ha de asumir la plena validez de lo establecido por la autoridad de origen tanto en materia de requisitos de acceso a la actividad como en relación con la circulación de bienes, sin que ese reconocimiento venga condicionado por la existencia de equivalencia alguna» ${ }^{23}$. Con ello el TC está rechazando la utilización del denominado "principio de país de origen» ${ }^{24}$ como instrumento válido dirigido a la armonización regulatoria entre CC.AA.

Por otra parte, tampoco produce el anteriormente aludido efecto armonizador sino que, por el contrario, al imponer la aceptación incondicionada por parte de la autoridad de destino de lo establecido en materia de requisitos de acceso a la actividad económica por parte de la autoridad de origen en aplicación del principio

en el Tratado de Funcionamiento UE (arts. 53, 67, 70, 81, 82). En buena medida, sus postulados resultan extrapolables a la problemática aquí tratada. Entre la amplia literatura sobre dicho principio resultan aquí de utilidad el trabajo de T. DE LA QUADRA-SALCEDO FERNÁNDEZ DEL CASTILLO, "Libertad de establecimiento y de servicios: ¿Reconocimiento mutuo o país de origen?”, Revista Española de Derecho Administrativo, núm. 146, 2010, págs. 221-263; el más reciente de J. AGUDO GONZÁLEZ, "La administración del reconocimiento mutuo. Un análisis a partir de la libre circulación de profesionales... hasta la unidad de mercado", Revista de Administración Pública, núm. 197, 2015, págs. 345-398; y F. JIMÉNEZ GARCÍA, "Variaciones sobre el principio de reconocimiento mutuo y la Directiva 2006/123/CE en el marco de la libre prestación de servicios", Revista de Derecho Comunitario Europeo, núm. 28, 2007, págs. 777-817.

22 Por cierto que en el FJ 12,c) se incurre en una inexactitud al afirmar que el «principio de eficacia nacional pretende, según el preámbulo de la Ley 20/2013, recoger el de reconocimiento mutuo desarrollado en el Derecho de la Unión Europea». En realidad el preámbulo de la LGUM declara que el principio de eficacia nacional se basa «en un criterio de confianza mutua» (apartado I, octavo párrafo, posteriormente reiterado en el apartado II noveno párrafo de dicho preámbulo). En este sentido, S. MUÑOZ MACHADO ya había criticado que el legislador hubiera fundamentado en la confianza mutua y el reconocimiento implícito, «que el legislador presume, sin ningún fundamento», la eficacia extraterritorial de decisiones adoptadas por otras administraciones públicas, considerando que una ley del Estado no puede imponer el reconocimiento mutuo de resoluciones o normas basado en una «confianza mutua» o «reconocimiento implícito» no manifestados por las entidades afectadas, ya que la eficacia extraterritorial de una decisión solo puede organizarse sobre la base de su reconocimiento por la autoridad de destino; "Sobre el restablecimiento legal..", cit., 2014, pág. 19.

${ }^{23} \mathrm{La}$ existencia del mencionado atributo de equivalencia como premisa para una correcta aplicación del reconocimiento mutuo en relación con la LGUM había sido ya señalada, entre otros, por C. PADRÓS REIG y J. M. MACÍAS CASTAÑO, cit., págs. 126-127; J. AGUDO GONZÁLEZ, ob. cit., pág. 390; I. URRUTIA LIBARONA, cit., págs. 234-235; y J. SOLA TEYSSIERE, "EI principio de eficacia nacional de los medios de intervención de acceso a las actividades económicas", Revista Española de Derecho Administrativo, núm. 179, 2016, pág. 239.

${ }^{24}$ Como han notado B. LOZANO CUTANDA e I. FERNÁNDEZ PUYOL, "Sentencia del Tribunal Constitucional 79/2017 sobre la Ley de Garantía de la Unidad de Mercado: la anulación de la «licencia única»", Diario La Ley, núm. 9.058, Sección Tribuna, 10 de Octubre de 2017, que también recuerdan cómo dicho principio se quiso incorporar a la Directiva de Servicios y fue, finalmente, rechazado. La traslación de dicho principio al derecho interno por la LGUM (región de origen) ya había sido señalada por la doctrina previa a la Sentencia. Así, M. J. ALONSO MAS consideraba que la LGUM establecía la aplicación de la regla del lugar de origen «sin paliativos»; "La eficacia de los títulos habilitantes...", pág. 331. También J. AGUDO GONZÁLEZ estimaba que la LGUM había «optado por la maximización del principio del "país (Comunidad Autónoma) de origen"»; cit., pág. 392. 
REALA. Nueva Época - N. ${ }^{11}$, Abril-Septiembre 2019 - ISSN: 1989-8975 - DOI: 10.24965/reala.v0i11.10632 - [Págs. 29-55]

Ordenación de las actividades económicas tras las sentencias del Tribunal Constitucional sobre la Ley de Unidad de Mercado

Javier Sola Teyssiere

de eficacia, en realidad «permite la subsistencia de una pluralidad de regímenes jurídicos cuya aplicación depende del criterio de la procedencia del operador económico» (FJ 12 in fine $)^{25}$.

Respecto a la alegación de contravención del principio de territorialidad de las competencias, el TC trae a colación, conforme a su doctrina anterior, la distinción entre el ejercicio de las competencias autonómicas que, como regla, debe limitarse al ámbito territorial correspondiente, y los efectos del ejercicio de dichas competencias, que sí podrían manifestarse fuera de dicho ámbito.

Atendiendo a ello, no niega el Tribunal la habilitación del Estado para dictar una normativa reconociendo efectos extraterritoriales a determinadas actuaciones de las administraciones autonómicas, con base en el artículo 149.1.13 CE. Pero, subraya que «la competencia del Estado para regular el reconocimiento mutuo y para otorgar eficacia supraterritorial a ciertas normas y actos administrativos autonómicos, solo es constitucionalmente admisible si se respeta un presupuesto: la equivalencia en la protección del legítimo objetivo pretendido por parte de las normas y actos del lugar de origen y los del lugar de destino» (FJ 13,a).

En ausencia de dicha condición no es legítimo excepcionar el principio de territorialidad obligando, por el contrario, a una Administración autonómica a aceptar un estándar distinto al fijado en su propia normativa. Básicamente porque ello supondría una constricción de su autonomía y «tener que aceptar dentro de su territorio una pluralidad de políticas ajenas» (FJ 13,a).

La Sentencia, haciéndose eco de argumentos materiales aducidos previamente por la doctrina y determinados órganos consultivos, estima que el aludido efecto extraterritorial derivado de la aplicación del principio de eficacia, aunque «no supone una modificación formal del sistema de distribución de competencias», produce un «desplazamiento» ${ }^{26}$ de la normativa aplicable en el territorio de destino y, así, un "vaciamiento» ${ }^{27}$ de contenido o «menoscabo» ${ }^{28}$ de las competencias formalmente atribuidas a la Comunidad Autónoma de destino (FJ 13.b).

Llamativamente, señala el Tribunal, la LGUM se aparta así de su objetivo armonizador declarado permitiendo, por el contrario, que las condiciones de acceso de las empresas a la actividad económica y de los productos al mercado puedan ser diferentes en los diecisiete territorios autonómicos.

25 Algunos informes de órganos consultivos así como una numerosa doctrina habían venido denunciando no sólo la carencia de efecto armonizador de la LGUM y subsiguiente mantenimiento de una diversidad regulatoria potencialmente «fragmentadora» que el legislador declaraba tratar de evitar sino, incluso, el eventual peligro de que la LGUM alentara la aparición de una competencia regulatoria a la baja o «dumping regulatorio» entre CC.AA., tendente a atraer a las empresas de nueva creación a sus territorios. Así en el Dictamen del Consejo Económico y Social, de 18 de abril de 2013, págs. 9 y 14; en el Dictamen 5/2014, de 14 de febrero, del Consell de Garanties Estatutàries de Cataluña, pág. 23. En la doctrina, entre otros, J. TORNOS MAS, cit., 2014, pág. 160; G. FERNÁNDEZ FARRERES, cit., 2014, pág. 139; C. PADRÓS REIG y J. M. MACÍAS CASTAÑO, cit., 2014, pág. 129; J. GIFREU FONT, "La impronta de la Directiva de servicios y de la normativa de transposición interna estatal en las técnicas interventoras urbanísticas. Parada y fonda: la Ley de garantía de la unidad de mercado", Revista Vasca de Administración Pública, núm. 98, 2014, págs. 205 y 210; M. CARLÓN RUIZ, cit., págs. 152 y 156; M. REBOLLO PUIG, "El Estado Autonómico tras la Ley de Garantía de la Unidad de Mercado y sus principios de necesidad y eficacia nacional”, Revista Andaluza de Administración Pública, núm. 91, 2015, págs. 134-136; e I. URRUTIA LIBARONA, cit., pág. 231.

26 Cfr. J. TORNOS MAS, para quien el problema es que la normativa en materia económica del territorio de destino «perderá su eficacia en el propio territorio de la autoridad competente que la aprobó al verse desplazada por la normativa que trae bajo el brazo el operador económico»; ob. cit., pág. 161. El Consell de Garanties Estatutàries de Cataluña considera que las disposiciones y actos de la Comunidad Autónoma de destino «se verán desplazados por la regulación del "lugar de origen" que acompañe al operador económico, si le resulta más favorable para acceder a la actividad»; Dictamen 5/2014, de 14 de febrero, sobre la LGUM, FJ II.4.C. EI Consejo Consultivo de Andalucía también estima la inconstitucionalidad de los artículos 6, 19 y 20 de la LGUM por vulneración de diversas competencias autonómicas previstas en el Estatuto de Autonomía «sobre las que se proyectan las normas y actuaciones administrativas de la Comunidad Autónoma que se ven desplazadas por el principio de eficacia territorial en todo el territorio nacional»; Dictamen 193/2014, de 19 de marzo, sobre la LGUM, FJ III.1.B. Las cursivas son nuestras.

27 Cfr. G. FERNÁNDEZ FARRERES, en cuya opinión, la competencia autonómica «queda en parte vaciada de contenido, pues, aunque en términos formales se respeta, materialmente, atendiendo a sus consecuencias y efectos, queda limitada por razón del efecto extraterritorial que se reconoce al ejercicio de idéntica competencia por cualesquiera otras Comunidades Autónomas»; ob. cit., pág. 138. Para el Consell de Garanties Estatutàries de Cataluña, los artículos 19 y 20 de la LGUM «comportan un vaciamiento del contenido de las materias estatutarias relacionadas con los diversos ámbitos económicos [..] y vulneran las competencias relacionadas con actividades económicas reconocidas en el capítulo II del título IV EAC»; Dictamen 5/2014, de 14 de febrero, sobre la LGUM, FJ II.4.D. Las cursivas son nuestras.

28 El Consejo Consultivo de Andalucía entiende que «el artículo 19 de la LGUM puede ser considerado inconstitucional por menoscabo de las competencias autonómicas de contenido económico previstas en el capítulo II del título II del Estatuto de Autonomía»; Dictamen 193/2014, de 19 de marzo, sobre la LGUM, FJ III.5. La cursiva es nuestra. Por su parte, M. CARLÓN RUIZ afirma que la LGUM «asume sin matices la "ultraeficacia" de los regímenes de acceso a la actividad definidos territorialmente» y que esa novedad «rompe por sí misma con el elemental principio de territorialidad en el ejercicio de las competencias autonómicas»; ob. cit., pág. 152. También M. J. ALONSO MAS opina que la regulación de los artículos 19 y 20 LGUM «directamente alteran la eficacia territorial de las normas y de los actos de las CC.AA. y de las entidades locales»; "La eficacia de los títulos habilitantes...”, cit., pág. 330. 
A partir de ahí, el TC vincula el principio de territorialidad con las reglas de distribución de competencias y las que rigen las relaciones entre ordenamientos autonómicos, aseverando que la LGUM «va más allá del reconocimiento mutuo para actos ejecutivos adoptados bajo una normativa común, pues, al alterar la territorialidad que rige las competencias autonómicas, establece un nuevo criterio de relación entre los ordenamientos de las distintas Comunidades Autónomas, incidiendo directamente en el régimen constitucional de distribución de competencias entre el Estado y las Comunidades Autónomas, alterándolo sustancialmente» ${ }^{29}$. La aplicación del principio de eficacia implica la ruptura del principio de territorialidad y «supone también la alteración de las reglas que rigen las relaciones entre los distintos ordenamientos autonómicos» (FJ 13,b ${ }^{30}$.

En conclusión, el Tribunal considera que el principio de eficacia nacional, tal como ha sido configurado por la LGUM, es contrario al orden constitucional de distribución de competencias y, por consiguiente, inconstitucional, tanto por exceder del alcance de la competencia estatal reconocida en el artículo 149.1.13 CE como por vulnerar el principio general de territorialidad de las competencias autonómicas ${ }^{31}$. En consecuencia, la STC 79/2017, de 22 de junio de 2017, declara la inconstitucionalidad y consiguiente nulidad de los artículos 19 y 20 de la LGUM al completo y, por conexión, las letras b), c) y e) del apartado 2 del artículo 18 así como la disposición adicional décima de dicha Ley, al tener su fundamento en el principio de eficacia nacional. Posteriormente, la STC 110/2017, de 5 de octubre, en aplicación de la doctrina de la Sentencia anterior, considera que «la definición que se realiza en el artículo 6 del principio de eficacia es, por las mismas razones, igualmente inconstitucional y nula» (FJ 3).

Finalmente, conviene dejar constancia por su vinculación con lo anterior, que la STC 111/2017, de 5 de octubre, ha declarado también la inconstitucionalidad del artículo 21.2.c) de la LGUM que establecía que «las autoridades del lugar de fabricación serán las competentes para el control del cumplimiento de la normativa relacionada con la producción y los requisitos del producto para su uso y consumo». El TC sencillamente razona que el anterior precepto tiene como fundamento el principio de eficacia nacional ya declarado inconstitucional en los términos que se acaban de exponer. Y más concretamente discurre que, al haber declarado previamente por Sentencia 79/2017 la nulidad de la previsión contenida en el artículo 19 de que «cualquier producto legalmente producido al amparo de la normativa de un lugar del territorio español podrá circular y ofertarse libremente en el resto del territorio desde el momento de su puesta en el mercado», debe declarar igualmente la nulidad del artículo 21.2,c) «por estar directamente fundado en ella» (FJ 3,a), in fine).

\section{B) Acotación del alcance de la anulación del principio de eficacia}

La declaración de inconstitucionalidad de la regulación del principio de eficacia nacional dispuesta por la LGUM, dada la amplitud de su anulación (artículos 6, 19, 20, disposición adicional 10. ${ }^{\circledR}$ ) y partes de otros artículos vinculados [art. 18.2, letras b), c) y e) y art. 21.2, letra c)], puede provocar distorsiones en la ya de por si reticente implantación del régimen de supervisión de las actividades económicas dispuesto por aquella Ley.

No obstante, conviene poner de manifiesto varios factores que pueden contribuir a limitar el alcance de dichos potenciales efectos en la dinámica administrativa.

De entrada debe recordarse que la LGUM ha puesto el foco en establecer las reglas de determinación de la Comunidad Autónoma a la que corresponde el ejercicio de la función de supervisión de las actividades económicas en los supuestos de empresas que operen en el territorio de más de una de ellas ${ }^{32}$. Así que no por obvio debe dejar de acotarse que los supuestos en que el desarrollo de dichas actividades económicas no exceda el ámbito autonómico no deben resultar afectados por las potenciales disfunciones, así como tampoco los cada vez más limitados supuestos en los que la competencia de supervisión es retenida por el Estado.

29 Cfr. con las manifestaciones de J. TORNOS MAS quien considera que el principio de eficacia es una novedad de gran calado en cuanto supone la introducción de «un nuevo criterio de relación entre ordenamientos jurídicos» por lo que el susodicho principio «no tiene encaje en nuestro modelo constitucional de distribución de competencias», ob. cit., págs. 165 y 167 , respectivamente.

30 Cfr. con lo expresado por G. FERNÁNDEZ FARRERES, para quien el principio de eficacia constituye una novedad de bulto que altera sustancialmente el régimen constitucional de distribución de competencias entre el Estado y las CC.AA: «aun cuando el objetivo formal no sea, naturalmente, la modificación del actual régimen de distribución de competencias», la regulación adoptada provoca de hecho la alteración de dicha distribución; ob. cit., pág. 142.

31 Vid. el interesante análisis crítico que lleva a cabo J. AGUDO GONZÁLEZ sobre la doctrina de la STC 79/2017, especialmente centrado en el tratamiento que esta hace de la territorialidad de las competencias autonómicas y proponiendo otras posibilidades alternativas en relación con la extraterritorialidad en el ejercicio de las mismas; "La extraterritorialidad de las actuaciones jurídico-administrativas de las Comunidades Autónomas”, Revista de Administración Pública, núm. 206, 2018, págs. $131-145$.

32 Sin predeterminar la Administración (autonómica, local) competente en cada caso, que vendrá determinada por el régimen de competencias y organización propio de cada Comunidad. 
En segundo lugar, ha de tenerse en cuenta la vigencia de una regla de efecto similar a la del principio de eficacia dispuesta en el artículo 7.3 de la Ley Paraguas, que dispone: «La realización de una comunicación o una declaración responsable o el otorgamiento de una autorización permitirá al prestador acceder a la actividad de servicios y ejercerla en la totalidad del territorio español, incluso mediante el establecimiento de sucursales». A partir de que el prestador quede así habilitado, el artículo permite a las autoridades disponer medios de intervención (autorizaciones, declaraciones responsables) relacionados con los establecimientos físicos en los que aquel ejerza sus actividades, con la limitación expresa de no «contemplar requisitos que no estén ligados específicamente» a dichos establecimientos físicos ${ }^{33}$.

Esta regla -insistimos, de efecto similar, en lo básico, a la del principio de eficacia- se sigue por tanto aplicando a los servicios. Lo que implica abarcar mucho, dada la importancia económica del sector servicios y del peso porcentual del número de sus operadores. Por otra parte, ha de notarse que es respecto a dichos operadores donde la regla de la eficacia nacional encuentra una mayor aplicación debido a su ubicuidad o, dicho de otro modo, su potencial movilidad y frecuente falta de atadura a un específico establecimiento físico (a diferencia, por ejemplo, de la industria).

Conviene reparar, por otra parte, que las autoridades de destino competentes sí pueden y deben ejercer su función de control sobre los aspectos de infraestructura e instalaciones del eventual establecimiento físico utilizado por un operador de cualquier actividad económica para ejercerla en su territorio, lo que entendemos afecta especialmente a los Ayuntamientos.

En tercer lugar, no se pueden obviar los supuestos en los que las normativas autonómicas reguladoras de los requisitos de acceso a determinadas actividades económicas se basan en una normativa europea armonizada o una legislación estatal común que las vinculan, respecto a los que la existencia de distorsiones no parece previsible.

Por último, resulta conveniente señalar que, en ocasiones, se establecen en reglamentos autonómicos reguladores de actividades económicas las que podríamos denominar como cláusulas de reconocimiento inverso. Es decir, el reconocimiento normativo de la validez de títulos habilitantes obtenidos en otro territorio para operar en el propio; eso sí, normalmente sometidos a condición de equivalencia ${ }^{34}$.

A pesar de las apreciaciones anteriores, es de reconocer que quedan amplios ámbitos materiales de actividad respecto a los que la declaración de nulidad del principio de eficacia va a provocar, a buen seguro, una situación de inseguridad jurídica indeseable. Además, la anulación de la regulación de dicho principio «desactiva» en buena medida el sistema de distribución de las competencias de supervisión de los operadores económicos, establecido igualmente en la LGUM (Capítulo VI), basado en el tándem autoridad de origen/ autoridad de destino $y$, por ende, estrechamente vinculado a la vigencia del principio de eficacia nacional, en cuanto constituye en cierto modo la instrumentación del mismo.

En este sentido, podría resultar perturbadora la anulación llevada a cabo de la letra c) del artículo 21.2 de la Ley en combinación con el artículo 19.2, si llegara a generar duplicidad de controles no justificados en relación con la fabricación y requisitos de los productos ${ }^{35}$.

En nuestra opinión, la situación tras las SSTC en este aspecto es que la autoridad del lugar donde se ubique la instalación necesaria para la producción es la competente para el control y la supervisión de a) las condiciones de las instalaciones y b) de los procesos de fabricación (incluyendo, en su caso, la exigencia de

33 La actual redacción del precepto fue introducida por la Disposición Final segunda de la LGUM, que también fue recurrida -pero no en conexión con el principio de eficacia-y que no ha sido declarada inconstitucional por la Sentencia $79 / 2017$.

34 V. gr. Decretos reguladores de la actividad de agencias de viajes, guías de turismo, etc. Como curiosidad, el Anteproyecto de LGUM de 24 de enero de 2013, incluía un apartado 4 en su art. 20 en el que se establecía que «la normativa autonómica o local que regule condiciones, obligaciones y procedimientos administrativos dirigidos a los operadores económicos, contemplará la validez del régimen aplicable a los operadores económicos establecidos en otros lugares del territorio nacional», que fue suprimido antes de su envío al Congreso siguiendo la sugerencia del Dictamen del Consejo de Estado que lo estimaba superfluo, «en cuanto regula el deber de adecuación de la normativa autonómica de desarrollo a la legislación básica estatal» derivando "ya dicho mandato de la propia construcción del sistema de reparto de competencias previsto en la Constitución» (Dictamen citado, observación 18). Por cierto que en el preámbulo subsiste una referencia expresa a dicho apartado cuando se dice que en el Capítulo V se regula «la previsión expresa en la normativa autonómica o local de la validez del régimen aplicable a los operadores establecidos en otros lugares del territorio» que, tras la supresión de aquel, no fue actualizada.

35 Riesgo que entendemos cabe relativizar pues, como hemos podido detectar, las quejas relativas a la existencia de distorsiones regulatorias en relación con los productos no han sido demasiado frecuentes, probablemente debido a que los requisitos más relevantes de los productos para su uso o consumo, esto es, los referidos a su seguridad y salubridad, con frecuencia están regulados a nivel nacional, o incluso armonizados a través de Directivas técnicas a nivel europeo. Vid. al respecto J. SOLA TEYSSIERE, "Unidad de mercado y supervisión administrativa...", cit., 2015, pág. 167. 
personal cualificado), requisitos de seguridad (que puede incluir un régimen de autorización u otro control previo sobre productos específicos), estándares de calidad, etcétera; para lo que podrá recurrir a la toma de muestras, análisis y controles de calidad y demás técnicas administrativas pertinentes de control de los fabricantes. De otro lado, la supervisión de los requisitos relativos al «uso y consumo» de los productos, que afectan más bien a los distribuidores que a los fabricantes, en tanto frecuentemente referidos a aspectos vinculados a la comercialización de los productos (etiquetado, conservación, caducidad, presentación, etc.), corresponderá a las autoridades competentes en materia de consumo y comercio donde se produzca el ejercicio de la actividad de comercialización del producto.

Por otra parte, al no haber entrado el TC en el examen de las letras a) y b) del apartado 2 del artículo 21 por una cuestión procesal ${ }^{36}$, obviamente estas permanecen en vigor. No obstante, al hallarse el entero artículo estrechamente vinculado a la ejecución y efectividad del principio de eficacia de las actuaciones administrativas en todo el territorio nacional, el hecho de que se haya declarado la inconstitucionalidad de este último principio hace perder a aquel artículo la médula de su sentido y funcionalidad.

Como es sabido el artículo 21 de la LGUM establece las reglas de determinación de la autoridad competente para la supervisión de los operadores económicos ${ }^{37}$. De esta forma, en su apartado 2 se establece que «cuando la competencia de supervisión y control no sea estatal:

a) Las autoridades de origen serán las competentes para la supervisión y control de los operadores respecto al cumplimiento de los requisitos de acceso a la actividad económica.

b) Las autoridades de destino serán las competentes para la supervisión y control del ejercicio de la actividad económica.»

El precepto establece así unas reglas de aplicación general dirigidas a garantizar una supervisión administrativa adaptada a los nuevos postulados que la propia Ley incorporaba y, muy específicamente, al principio de eficacia en todo el territorio nacional mencionado ${ }^{38}$, con el que conjuntamente formaba un sistema. El problema ahora es que al ser dicho artículo tributario de la regulación del principio de eficacia, con la anulación de este último, dicho sistema queda mermado y huérfano de los principios en que se fundamentaba su cumplimiento. Dicho de otra forma: las reglas siguen en vigor pero ha desaparecido el elemento que las completaba.

No obstante, en nuestra opinión, así como algunas situaciones de entre las encuadrables en la letra a) anterior podrían ser potencialmente problemáticas, no tiene por qué ocurrir lo mismo con las previstas en la letra $b$ ).

Efectivamente, la regla competencial de la letra a), consistente en que la autoridad de origen es la competente para el control de los requisitos de acceso a una actividad económica, adquiría su pleno sentido en el contexto de lo dispuesto en el artículo 19, del cual era su complemento. En realidad, el enunciado anterior, de que la autoridad de origen es la competente para la actuación de control del acceso conforme a los requisitos dispuestos en su normativa, se completaba con el deber de la autoridad de destino de asumir la plena validez de dicha actuación aunque su propia normativa estableciera requisitos distintos para acceder a dicha actividad en su territorio (art. 19.3). A falta de este último mandato legal, anulado por el TC, se vuelve a la situación anterior, traducible en que de nuevo nada impide que una Comunidad Autónoma en la que un operador, ya establecido en otro lugar, decida ahora establecerse, estime necesario someter a dicho operador al control del cumplimiento de sus propios requisitos de acceso dispuestos en su territorio conforme a su normativa propia. La eliminación del carácter extraterritorial de la habilitación de origen -ínsito en el principio de eficacia nacional anulado-, podría así llevar a la consideración de que el establecimiento de un operador ya habilitado en un lugar, en un nuevo territorio, supone el primer acceso a la actividad en este último territorio, en el cual la Administración competente puede someterlo a control de los requisitos de acceso a la actividad vigentes en el mismo, actuando, por así decirlo, como nueva «autoridad de origen» ${ }^{39}$. La situación

${ }^{36}$ En la Sentencia 111/2017, el TC precisa que, aunque el Consejo de Gobierno de la Junta de Andalucía había recurrido los apartados 2 y 3 del artículo 21, posteriormente la impugnación «solo aparece acompañada de la inexcusable fundamentación respecto de la letra c)» del apartado 2, por lo que limita su examen solo a dicha letra.

37 Sobre el sistema de supervisión puede verse nuestro trabajo J. SOLA TEYSSIERE, "Unidad de mercado y supervisión administrativa de las actividades económicas", cit., págs. 133-174 (en especial págs. 146 ss.)

${ }_{38}$ También al principio de simplificación de cargas recogido en su artículo 7 tendente, junto al de eficacia, a evitar duplicidades en los casos de potencial concurrencia de varias administraciones en el ejercicio de las potestades de control.

39 Lo cual, así entendido, no está en contra de la dicción literal de la letra a) del artículo 21.2 ni de la definición de «autoridad de origen» contenida en el Anexo de la LGUM. 
REALA. Nueva Época - N. ${ }^{\circ}$ 11, Abril-Septiembre 2019 - ISSN: 1989-8975 - DOI: 10.24965/reala.v0i11.10632 - [Págs. 29-55]

Ordenación de las actividades económicas tras las sentencias del Tribunal Constitucional sobre la Ley de Unidad de Mercado

Javier Sola Teyssiere

descrita podría en teoría reproducirse en cada territorio, con lo que cabría el riesgo de mantener o generar nueva fragmentación contra la que la LGUM declaraba enfáticamente combatir.

En todo caso, conviene de nuevo reiterar que de la potencial problemática descrita hay que excluir:

a) Las actividades de servicios, amparadas por la regla de eficacia nacional de la Ley Paraguas,

b) Las actividades cuyos requisitos de acceso se basan en una normativa europea armonizada o una legislación estatal común.

c) El ámbito de las funciones de control sobre los aspectos de infraestructura e instalaciones del eventual establecimiento físico a utilizar por el operador para ejercer su actividad que, antes y después de la LGUM, siempre ha estado lógicamente bajo la competencia de la Administración del lugar de ubicación, especialmente de los Ayuntamientos.

Por lo que cabe acotar que el ámbito de los «requisitos de acceso» potencialmente afectado por la problemática que acabamos de describir se circunscribe, en realidad, a aquellos elementos no vinculados a los establecimientos físicos, como pueden ser requisitos relativos a elementos subjetivos concernientes al operador (constitución formal de la empresa), condiciones relativas a sus gestores o personal (cualificación profesional) o garantías (seguros, fianzas); coincidentes, básicamente, con los «requisitos, cualificaciones, controles previos o garantías» a que se referían el artículo 19.3 LGUM y, más detalladamente, las también anuladas letras b), c) y e) del artículo 18.2 (homologaciones, acreditaciones, calificaciones, certificaciones cualificaciones, reconocimientos, especificaciones técnicas, etcétera), exigibles en el momento de acceso a su actividad a los operadores económicos que se encuentren fuera del ámbito de aplicación de la Ley Paraguas.

Contribuiría a evitar situaciones problemáticas la activación de actuaciones de cooperación tendentes a promover una estandarización de los requisitos aludidos, a través de las vías previstas en la propia LGUM -ex-ante al elaborar los proyectos normativos (art. 14) o ex-post en el seno de las Conferencias Sectoriales (art. 12)-. Más si en la normativa de plasmación de dicha cooperación se introdujeran expresamente cláusulas de reconocimiento mutuo de la validez de títulos habilitantes obtenidos en otro territorio para operar en el propio; aunque fueran sometidas a condición de equivalencia.

Como decíamos anteriormente, la potencial problemática aludida no tiene por qué extenderse a los supuestos comprendidos bajo la letra b) del apartado 2 del artículo 21 , en relación con las funciones de las denominadas autoridades de destino.

En nuestra opinión, la autoridad competente para supervisar los requisitos de ejercicio de una actividad económica es, sencillamente, la del territorio donde se desarrolla dicha actividad, a cuya normativa sobre este aspecto queda sometido el operador económico, sin que esta regla haya resultado alterada por las SSTC de 2017.

La normativa autonómica, especialmente la reglamentaria, reguladora de las distintas actividades económicas suele contener un conjunto de requisitos, deberes, limitaciones o prohibiciones atinentes al funcionamiento y la gestión ordinaria de la actividad una vez iniciada, que conforman jurídicamente la disciplina de ejercicio de dicha actividad. Se establecen así requisitos vinculados estrictamente al ejercicio de la actividad, tales como la gestión de hojas de reclamaciones en los establecimientos, las exigencias informativas hacia los consumidores y usuarios, las condiciones de comercialización de productos o servicios o los requisitos de conservación de los productos para su venta, entre otros muchos. La supervisión y control sobre su cumplimiento ha de ser in situ, correspondiendo a la Administración, competente en la materia, del territorio donde dichas actividades se desarrollan.

\section{El aval del TC al sistema de limitación de los medios de intervención administrativa sobre las actividades económicas}

El otro eje central de la LGUM es el que ha sido calificado como principio de intervención mínima ${ }^{40}$, que supone la implantación de un sistema de limitación de los medios de intervención administrativa sobre las actividades económicas.

Dicho sistema aparece desplegado en la Ley principalmente través de tres artículos. En primer lugar el artículo 5, que enuncia el principio de necesidad y proporcionalidad de las actuaciones de las autoridades

\footnotetext{
40 Así, J. LEÓN SANZ, cit., págs. 40-41.
} 
que supongan límites a la libertad de empresa. En segundo lugar el artículo 17, que delimita (en positivo) los requisitos de los principales medios de intervención sobre las actividades económicas utilizados por las Administraciones pública. Por último el artículo 18, que establece (en negativo) una larga lista de actuaciones que se califican como no conformes con la Ley y que, por tanto, han de entenderse prohibidas.

En concreto, la Ley restringe los posibles motivos justificativos del establecimiento de autorizaciones, declaraciones responsables y comunicaciones a unas concretas razones imperiosas de interés general, especialmente constreñidas en el caso de que la medida de intervención a utilizar sea una autorización. El efecto más notorio de este despliegue es que introduce una estricta limitación a las posibilidades regulatorias de las autoridades autonómicas y locales para disponer requisitos de acceso y de ejercicio a las actividades económicas. Esta situación ya fue objetada por el Consejo de Estado ${ }^{41}$ durante la tramitación de la Ley, siendo posteriormente criticada por la doctrina ${ }^{42} \mathrm{y}$, finalmente, fue objeto de recurso de inconstitucionalidad ${ }^{43}$.

La STC 79/2017 encuadra su examen de los preceptos aludidos como una controversia competencial. Considera que la parte recurrente no cuestiona la competencia estatal para dictar normas básicas de ordenación global de la economía al amparo del artículo 149.1.13 CE, sino que plantea que la LGUM, al constreñir en exceso las competencias sectoriales de las Comunidades Autónomas al amparo de dicho título, está impidiendo la regulación autonómica reconocida estatutariamente. En concreto se entiende que la LGUM impone una limitación injustificada de los medios de intervención administrativa de que dispone la Comunidad Autónoma concernida, impidiéndole decidir la técnica que considere más apropiada para compatibilizar el acceso y ejercicio de actividades económicas con la garantía de los eventuales intereses públicos afectados. EI TC aborda su respuesta diferenciando dos cuestiones.

La primera se refiere a la constitucionalidad del apartado primero del artículo 5 de la LGUM, en cuanto exige justificar los límites y requisitos al acceso o al ejercicio de una actividad económica en la salvaguarda de alguna de las razones imperiosas de interés general que específicamente se recogen en el artículo 3.11 de la Ley Paraguas. Tras constatar que la LGUM ha optado por establecer una lista cerrada de razones frente al carácter abierto de las mismas en el Derecho de la Unión Europea y otras reflexiones y cautelas, concluye el TC estimando la constitucionalidad del precepto aludido, en tanto que «en el presente supuesto no se produce tal efecto restrictivo sobre la autonomía, pues la enumeración que se realiza en el artículo 3.11 de la Ley 17/2009, es lo suficientemente abierta en sus términos como para que quepan dentro de aquella los diferentes objetivos que se pueden querer promover a través del amplio elenco de competencias autonómicas» y, por tanto, para que las Comunidades Autónomas puedan desarrollar sus competencias (FJ 7,a).

La segunda se refiere a la constitucionalidad del artículo 17.1 de la Ley, que reduce aquellas concretas razones imperiosas de interés general que pueden justificar la exigencia de una autorización. También estima en este caso la constitucionalidad del precepto controvertido argumentado que es conforme con la Constitución «que el Estado promueva el objetivo económico de que se reduzcan las cargas administrativas para el acceso y ejercicio de una actividad económica, sin que ello suponga el menoscabo de aquellos intereses a proteger, pues la norma permite bien el establecimiento de mecanismos de control distintos que tendrán lugar con carácter previo (declaración responsable, comunicación previa), bien el establecimiento

41 El Dictamen del Consejo de Estado al anteproyecto de LGUM, de 26 de junio de 2013, ya puso objeciones a la restricción de razones para la exigencia de una autorización operada por el artículo 17, considerándolas insuficientes y estimando que dicho precepto debería remitirse a las más amplias razones imperiosas de interés general acogidas en el artículo 5 . Para el Consejo de Estado, el artículo 17 «no puede reconstituir o reorganizar todo el sistema autorizatorio de las autoridades competentes en materia de actividades competentes» (observación 13). Más explícitamente, el interesante voto particular del Consejero permanente E. Alonso García, calificaba el precepto de «flagrantemente inconstitucional».

42 Así M. REBOLLO PUIG, estima que la restricción de los posibles motivos justificativos del establecimiento de autorizaciones, declaraciones responsables y comunicaciones a unas concretas razones imperiosas de interés general no tiene fundamento en el Derecho comunitario ni tampoco en el principio de unidad de mercado que garantiza la Constitución. Entiende que, si ya la normativa de transposición española fue más allá de lo que exigía la Directiva de Servicios en materia de regulación de los medios de intervención pública sobre las actividades económicas, ahora la LGUM la desborda sobradamente (pág. 29). Para este autor, «no es posible aceptar que una Ley estatal realice esa operación en bloque y para cualquier sector, incluidos los de competencia autonómica exclusiva» por lo que concluye valorando la disconformidad del artículo 5 de la LGUM con la Constitución (pág. 32); vid. "La libertad de empresa...", cit., 2014, págs. 23-33 in totum. Igualmente se pronuncian críticamente sobre el alcance dado al principio de necesidad y proporcionalidad en relación con las autorizaciones G. FERNÁNDEZ FARRERES, cit., en especial págs.125-131, e I. URRUTIA LIBARONA, cit., págs. 214-217.

43 Los Recursos de inconstitucionalidad presentados por el Parlamento y el Gobierno catalán se dirigen, entre otros, contra los artículos 5, 17 y 18, que son los que básicamente contienen la regulación puesta en cuestión; mientras que el interpuesto por el Gobierno andaluz también, aunque parcialmente, contra los artículos 17 y 18. 
REALA. Nueva Época - N. ${ }^{11}$, Abril-Septiembre 2019 - ISSN: 1989-8975 - DOI: 10.24965/reala.v0i11.10632 - [Págs. 29-55]

Ordenación de las actividades económicas tras las sentencias del Tribunal Constitucional sobre la Ley de Unidad de Mercado

Javier Sola Teyssiere

de condiciones de ejercicio de la actividad económica cuyo cumplimiento siempre podrá ser controlado con posterioridad» $(\mathrm{FJ} 7, \mathrm{~b})^{44}$.

Sobre las limitaciones dispuestas en el artículo 17.1, la STC 111/2017 añade alguna apreciación de interés al considerar que dichas previsiones «en modo alguno imponen restricciones a la libre circulación de bienes o personas en todo el territorio español, ni desarrollan medidas que, por considerarse proteccionistas o discriminatorias, puedan llegar a vulnerar el artículo 139.2 CE. Tampoco restringen la libertad de empresa (art. $38 \mathrm{CE}$ ); antes bien, reiteran o concretan las garantías que resultan de su reconocimiento constitucional e, incluso, suponen una elevación legal del estándar de protección que el artículo 38 CE garantiza» (FJ 4,b).

Con estos pronunciamientos, en definitiva, se puede decir que el TC ha avalado el sistema de limitación de los medios de intervención de las actividades económicas dispuesto por la LGUM.

\section{La malograda Ley de Garantía de la Unidad de Mercado no garantiza la unidad de mercado, pero sí mantiene su carácter desregulador}

La LGUM era, y es tras las Sentencias del Tribunal Constitucional examinadas, más que nada una norma de corte desregulador, fundamentalmente orientada a la mejora de la competitividad, que instrumentalmente considera la unidad de mercado como un «principio económico esencial para el funcionamiento competitivo de la economía española» (párrafo primero del preámbulo). Competitividad que según el legislador se ve amenazada por la fragmentación del mercado «provocada por el exceso y dispersión de producción normativa en los sectores económicos» ${ }^{45}$. Es más, no parece desatinado afinar la opinión expresada manifestando que la LGUM supone una operación desregulatoria especialmente diseñada frente a la legislación autonómica ${ }^{46}$.

Ya con anterioridad a las SSTC de 2017, cabía manifestar que ninguno de los dos puntales sobre los que se asienta la LGUM (el principio de eficacia nacional y el sistema de limitación de los medios de intervención administrativa sobre las actividades económicas) suponían una armonización directa de las normativas autonómicas, cuyos efectos distorsionantes la ley que se autoproclama de garantía de la unidad de mercado declaradamente se proponía corregir ${ }^{47}$. Por el contrario, el legislador evitó imponer abiertamente una armonización positiva, optando por promover una integración negativa ${ }^{48}$ : lo realmente relevante era liberalizar el acceso a las actividades económicas a través de la remoción de los obstáculos existentes o potenciales que pudieran afectar a la competitividad. Mientras, solapadamente, daba la sensación de que se incitaba a la diversidad (des)regulatoria a la baja que pudiera favorecer la competencia ${ }^{49}$.

Debe insistirse, por tanto, en que la LGUM no armoniza la regulación de los requisitos de acceso a las actividades económicas ni, mucho menos, los requisitos de ejercicio de dichas actividades sobre los que, como explicaremos más adelante, las CCAA siguen gozando de amplio margen de disposición. La aplicación de los dos elementos centrales de la Ley no asegura como resultado la eliminación de las denunciadas distorsiones del mercado, consintiendo la subsistencia de requisitos diferentes para el acceso a la misma actividad económica dependiendo del territorio, así como de condiciones distintas respecto al ejercicio de dicha actividad una vez en funcionamiento ${ }^{50}$.

${ }_{44}$ Sobre la posibilidad apuntada de establecimiento de condiciones de ejercicio de las actividades, la posterior STC 111/2017, reitera que el sistema limitador dispuesto por el artículo 17.1 de la LGUM «no impide que las autoridades competentes "establezcan, respecto de la actividad de que se trate, condiciones materiales destinadas a objetivos legítimos distintos" de los enumerados taxativamente» $(\mathrm{FJ} 4, \mathrm{~b})$.

${ }^{45}$ Así en la Memoria del Análisis de Impacto Normativo del Anteproyecto de LGUM, de 24 de enero de 2013, pág. 9. En el preámbulo de la LGUM se achaca a la indicada fragmentación, entre otras consecuencias negativas, la de generar un elevado coste para la actividad empresarial y la de reducir la productividad, la competitividad, el crecimiento económico y el empleo. En opinión de J. NARBÓN FERNÁNDEZ, sin embargo, la LGUM «se ha aprobado sin un fundamento sólido y sin una evaluación objetiva de la supuesta fragmentación del mercado, que se presenta como un hecho evidente, sin medir las consecuencias y el impacto de su regulación»; "Los discutibles presupuestos económicos de la Ley de Garantía de la Unidad de Mercado", Revista Española de Derecho Administrativo, núm. 175, 2016, pág. 190.

46 Para M. REBOLLO PUIG, dado que el legislador estatal podrá seguir imponiendo límites a la libertad de empresa a través de leyes posteriores, «la novedad y la cuestión crucial están, pues, en el límite que el artículo 5 LGUM impone a los Parlamentos autonómicos», por lo que considera que la LGUM «es sólo una garantía de la libertad de empresa frente a las leyes autonómicas»; "La libertad de empresa tras...", cit., (2014), pág. 32.

47 Vid. en este sentido J. SOLA TEYSSIERE, “Unidad de mercado y supervisión..", cit., 2015, pág. 143.

48 Vid. al respecto LEÓN SANZ, J., cit., pág. 37.

49 De ahí las advertencias del riesgo de que la LGUM propiciara una competencia regulatoria a la baja o «dumping regulatorio» entre CC.AA., formuladas por algunos órganos consultivos y relevante doctrina; citados en nota 25 supra.

50 La LGUM se ha apartado así del objetivo encomiable de propiciar una regulación armonizadora de los requisitos de acceso y ejercicio de las actividades económicas en los casos en que se considerara necesario, para cuya consecución quizás hubiera sido más 
En concreto, la regulación del principio de eficacia llevada a cabo por la LGUM no aseguraba la implantación de un basamento normativo común, que atendiera a la necesidad de exigir unos requisitos de acceso, para las distintas actividades económicas, análogos o comparables, que aseguraran un estándar de protección equivalente de los intereses generales afectados en todo el territorio nacional. En consecuencia, su anulación no ha supuesto un giro radical en los objetivos reales perseguidos por la LGUM que ni anteriormente garantizaba, ni actualmente garantiza, la unidad de mercado entendida en un sentido positivo ${ }^{51}$.

Ciertamente, la declaración de inconstitucionalidad de los artículos relativos al principio de eficacia y algunos adyacentes sí puede reactivar la exigencia de requisitos de acceso a operadores ajenos al sector servicios ya establecidos en un territorio y que pretendan establecerse en otro, por parte de las autoridades de este último, al desaparecer la obligación de reconocimiento del título habilitante de origen.

Se debilita así la veste desreguladora de la LGUM, al desactivar parcialmente una de las medidas que hubiera contribuido a la reducción de cargas administrativas para los operadores, evitando duplicidades, a la par que propiciaba una simplificación de las actividades de las Administraciones públicas, pero que ha sido víctima de una deficiente formulación.

No obstante, a pesar de esta afectación parcial, se mantiene el carácter fundamentalmente desregulador de la LGUM, al haber avalado el TC el sistema de limitación de los medios de intervención administrativa sobre las actividades económicas, que constituye el instrumento principal y de más fuerza en el cometido de realización de dicho objetivo ${ }^{52}$.

\section{EL ESQUEMA DE MEDIOS Y LÍMITES DE ORDENACIÓN}

EI TC, como se ha visto anteriormente, ha dejado casi intacto el sistema dispuesto por los artículos 5 , 17 y 18 de la LGUM ${ }^{53}$. Además, con excepción del anulado principio de eficacia, ha de considerarse que la ordenación de las actividades económicas, en todas sus manifestaciones, está sometida a la observancia del resto de principios enunciados en el Capítulo II de la LGUM: principios de no discriminación, cooperación y confianza mutua, necesidad y proporcionalidad de sus actuaciones, simplificación de cargas y transparencia.

Teniendo en cuenta estas consideraciones, abordamos seguidamente la explicación del esquema de instrumentos de intervención y sus límites, el ámbito de disposición de requisitos o condiciones materiales ligados al ejercicio de la actividad, finalizando con el examen de las actuaciones específicas que la propia Ley califica como no conformes.

adecuado adoptar actuaciones de integración positiva, como en la línea sugerida por J. TORNOS MAS de acudir, en primer lugar, a los instrumentos previstos en la propia LGUM de cooperación en la elaboración de proyectos normativos (art. 14) y a lo que se podría calificar como «armonización paccionada» o de elaboración conjunta de normativas homogéneas en el seno de las Conferencias Sectoriales (art. 12.2). Para el caso de que estas vías no fueran suficientes, continúa dicho autor, «podría pensarse de forma excepcional en recuperar la técnica de la ley de armonización» o recurrir a la competencia transversal estatal del artículo 149.1.13. ${ }^{2}$ de la Constitución «para aquellas intervenciones que sean necesarias por afectar al funcionamiento general de la economía»; "La ley 20/2013, de 9 de diciembre, de garantía de la unidad de mercado. En particular, el principio de eficacia", Revista d'Estudis Autonòmics i Federals, núm. 19, 2014, pág. 168; vid. especialmente su desarrollo de la propuesta de recurso a la ley de armonización en págs. 172-175. Incluye asimismo referencias a la posibilidad de recurrir a la competencia estatal del art. 149.1.13. ${ }^{a} \mathrm{CE}$ y a las leyes de armonización M. J. ALONSO MAS, "La eficacia de los títulos habilitantes en todo el territorio nacional y la aplicación de la regla del lugar de origen", en ob. col. El nuevo marco jurídico de la unidad de mercado. Comentario a la Ley de garantía de la unidad de mercado, Dir. M. J. Alonso Mas, Madrid, 2014, págs. 330-333; esta última ya sugerida en su momento por V. TENA PIAZUELO, "Defensa del principio de unidad mercado. Riesgo de fragmentación de los mercados a través de la regulación”, en ob. col. Marco regulatorio y unidad de mercado, Ed. Círculo de Empresarios, Madrid, 2006, pág. 354, y por F. MARCOS, A vueltas con la «unidad de mercado nacional», Working Paper IE Law School, AJ-177, 2011, págs. 6 y 15.

51 Para C. LENCE REIJA, la denominación de la LGUM resulta engañosa en tanto no da una idea de su verdadero alcance y matiza que «desde la STC 79/2017 que anuló los preceptos dedicados a la libertad de circulación, es evidente que la LGUM ya es solo una ley que regula la libertad de empresa»; "La tutela de la libertad de empresa frente a intervenciones administrativas desproporcionadas", Revista General de Derecho Administrativo, núm. 46, 2017, pág. 20, nota 37.

52 J. SOLANES MULLOR considera que se ha producido una mutación constitucional del principio de unidad de mercado avalada por el TC al considerar el nuevo sistema como una medida desreguladora legítimamente dictada por el Estado al amparo del artículo 149.1.13 de la Constitución. En palabras de este autor: «No se trata tanto, para el TC, de una reconfiguración del propio principio de unidad de mercado, sino más bien una medida de política económica que reconfigura el mercado nacional. Bajo esta perspectiva, deja de ser relevante para el TC el impacto territorial que exigía el principio de unidad de mercado, estamos ante otro tipo de cuestión, una medida desreguladora económica desligada del principio de unidad de mercado»; ob. cit., 2017, pág. 107.

53 Con la excepción de la declaración de inconstitucionalidad de las letras b), c) y e) del apartado 2 del artículo 18, derivada de su conexión con la anulación del principio de eficacia y su articulación. 
REALA. Nueva Época - N. ${ }^{11}$, Abril-Septiembre 2019 - ISSN: 1989-8975 - DOI: 10.24965/reala.v0i11.10632 - [Págs. 29-55]

Ordenación de las actividades económicas tras las sentencias del Tribunal Constitucional sobre la Ley de Unidad de Mercado

Javier Sola Teyssiere

\section{En relación con los instrumentos de intervención}

\section{A) Autorizaciones}

El apartado 1 del artículo 17 de la LGUM se ocupa del régimen de las autorizaciones estableciendo de entrada dos requisitos.

En primer lugar, deben ser establecidas por Ley, con la excepción de que se exijan por una norma comunitaria o tratado internacional, en cuyo caso podrán establecerse por norma reglamentaria ${ }^{54}$. Desde luego ha de rechazarse, como explícitamente ha hecho el TC, que de la LGUM se derive la exigencia de una Ley estatal para el establecimiento de autorizaciones ${ }^{55}$, pudiendo, obviamente, ser establecidas por medio de ley autonómica. Por otra parte, ha de admitirse como válida la habilitación formal por ley de la potestad autorizatoria a la Administración, normalmente complementada por un desarrollo reglamentario del régimen concreto (documentación exigida, procedimiento, plazos) de cada autorización.

En segundo lugar, la norma que establezca y regule la autorización debe motivar suficientemente su necesidad y proporcionalidad. La necesidad supone la justificación del instrumento autorizatorio en la protección de una razón imperiosa de interés general. El segundo elemento remite al sometimiento de aquella norma al denominado triple test de proporcionalidad desarrollado por la doctrina del TJUE que supone chequear: a) la idoneidad del instrumento dispuesto para conseguir el objetivo de protección prefijado; b) que dicho objetivo no pueda alcanzarse mediante la instauración de medidas menos restrictivas de la libertad de empresa (declaración responsable, comunicación) considerándose, por tanto, la autorización indispensable; c) la proporcionalidad en sentido estricto de la medida, ponderando el interés general de su implantación frente a la lesión al principio de libertad de empresa ${ }^{56}$.

Justificación, por tanto, de la necesidad y proporcionalidad a la que, por otra parte, vienen con carácter general obligadas las Administraciones en aplicación de los «Principios de buena regulación» dispuestos en el artículo 129 de la Ley 39/2015, de 1 de octubre, del Procedimiento Administrativo Común, así como en los «Principios de intervención de las Administraciones Públicas para el desarrollo de una actividad» recogidos en el artículo 4 de la Ley 40/2015, de 1 de octubre, de Régimen Jurídico del Sector Público.

En cualquier caso, la LGUM justifica directamente la concurrencia de los principios de necesidad y proporcionalidad para la exigencia de una autorización «cuando por la escasez de recursos naturales, la utilización de dominio público, la existencia de inequívocos impedimentos técnicos o en función de la existencia de servicios públicos sometidos a tarifas reguladas, el número de operadores económicos del mercado sea limitado ${ }^{57}$ (art. 17.1.c). Por otra parte, la Ley precisa que las inscripciones en registros que presenten un carácter habilitante «tendrán a todos los efectos el carácter de autorización» (art. 17.1 in fine $)^{58}$.

${ }^{54}$ Sobre la aplicación del requisito de reserva de ley por las corporaciones locales vid. las consideraciones expuestas por D. CANALS I AMETLLER, "Reforma de la Administración Pública y unidad de mercado: incidencias en el régimen de intervención municipal en la actividad económica privada", Cuadernos de Derecho Local, núm. 36, 2014, págs. 44-45.

55 En el recurso contra la LGUM interpuesto por el Parlamento de Cataluña, ante la, a nuestro juicio desacertada, lectura del artículo 16 de la Ley por parte del recurrente, que entiende que del mismo se deriva que sólo mediante ley estatal puede limitarse el acceso a las actividades económicas y su ejercicio, el TC afirma categóricamente que «de la lectura del artículo 16 de la Ley 20/2013 no se desprende que sólo mediante una Ley estatal pueda regularse y, en su caso, limitarse el acceso a las actividades económicas y su ejercicio» (STC 79/2017, FJ 6).

${ }^{56}$ Sobre el principio de necesidad y proporcionalidad en la LGUM y la doctrina del TJUE sobre el test de proporcionalidad, nos remitimos a las explicaciones y citas jurisprudenciales contenidas en el útil y sistemático trabajo de J. J. PERNAS GARCÍA, «EI "principio de necesidad y de proporcionalidad" en la Ley de Garantía de Unidad de Mercado» Revista de Direito Econômico e Socioambiental, Curitiba, vol. 6, núm. 2, 2015, págs. 54 a 72. También se refiere a los tres elementos del test de proporcionalidad M. REBOLLO PUIG, "El Estado Autonómico tras la Ley de Garantía..", cit., 2015, págs. 112-113. Un examen de aplicación del principio de proporcionalidad en relación concreta con unas ordenanzas locales reguladoras de infraestructuras de comunicaciones electrónicas es desarrollado en el trabajo de DE LA TORRE MARTíNEZ, L., "Los principios de proporcionalidad y de necesidad bajo el prisma de la garantía de la unidad de mercado: ¿nuevos condicionantes de las ordenanzas locales de telecomunicaciones?", Revista Española de Derecho Administrativo, núm. 181, 2016, págs. 191-225.

${ }^{57}$ En el preámbulo de la LGUM se consideran aquí incluidas, a título de ejemplo, las actividades desarrolladas por el taxi y el arrendamiento de vehículos con conductor, las concesiones demaniales o las oficinas de farmacia.

${ }^{58}$ La STC 97/2018, de 19 de septiembre, ha realizado una interpretación de conformidad de la inscripción de los agentes inmobiliarios en un Registro administrativo, prevista en la Ley vasca $3 / 2015$, condicionada a que se entienda que dicha inscripción tiene carácter voluntario (lo que no queda claro en el texto legal). Entre las consideraciones se indica, a contrario sensu, que de entenderse que la inscripción tuviera carácter habilitante para el ejercicio de dicha profesión no sería conforme por contrariar el artículo 17.1 de la LGUM, que tiene carácter de ley básica. 
Pero lo que realmente supone una novedad tremendamente restrictiva ${ }^{59}$ para las posibilidades regulatorias autonómicas ${ }^{60}$ sobre control administrativo preventivo de las actividades económicas, es el régimen dispuesto en las letras a) y b) del apartado 1 del artículo 17 de la Ley, a través de las que se establece un numerus clausus de razones imperiosas de interés general (RIIG) invocables para establecer autorizaciones.

En concreto, y en función del objeto, se distinguen dos supuestos:

A) Si la autorización es concerniente al operador económico (normalmente relativa al acceso a su actividad) ${ }^{61}$, solo puede justificarse en la protección de cuatro RIIG:

- Seguridad pública.

- Salud pública.

- Medio ambiente.

- Orden público.

B) Si la autorización es relativa a las infraestructuras o instalaciones en las que se vaya a desarrollar la actividad, solo puede justificarse en la protección de cinco RIIG:

- Seguridad pública.

- Salud pública.

- Medio ambiente.

- Entorno urbano.

- Patrimonio histórico-artístico.

Como puede observarse coinciden tres RIIG en ambos supuestos, mientras que, razonablemente, se admite el orden público como causa justificativa de imposición de autorización para el acceso a una actividad y, de otro lado, la protección del entorno urbano y del patrimonio histórico-artístico como valores más vinculados a la implantación de licencias para las edificaciones e instalaciones.

A partir de ahí, se plantea a los reguladores la tarea de delimitar el significado y alcance de cada una de las RIIG. Y dado que, a nivel legislativo interno, el artículo 3.11 de la Ley Paraguas, teniendo sin duda en cuenta el origen del concepto, define «Razón imperiosa de interés general» como «razón definida e interpretada la jurisprudencia del Tribunal de Justicia de las Comunidades Europeas», hay que convenir con REBOLLO PUIG que «parece obligado acudir a la jurisprudencia del Tribunal de Luxemburgo para delimitar, incluso a efectos internos, qué haya de entenderse por cada una de esas razones» ${ }^{62}$. Lo que, en opinión de este autor que compartimos, podrá facilitar la tarea aludida pero que, en todo caso, ni será sencilla ni logrará resolver todas las dudas ${ }^{63}$.

Excede del alcance de estas páginas el examen pormenorizado de los contenidos, alcance y límites de cada una de las RIIG a las que se refiere la LGUM. Pero sí cabe insistir en que, tras la entrada en vigor de la Ley 39/2015, del Procedimiento Administrativo Común, la aplicación de los principios de buena regulación contenidos en su artículo 129 debería llevar a los diferentes Gobiernos impulsores de algún anteproyecto de ley que prevea cualquier tipo de autorización a justificar razonadamente en su exposición de motivos la

${ }^{59}$ Criticada, como se indicó, tanto por el Consejo de Estado como por una relevante doctrina (vid. ap. Il.2 supra).

60 Como ha señalado REBOLLO PUIG, "el Estado podrá aprobar leyes que sometan actividades privadas a la obtención de una autorización sin que concurra alguna de las razones del artículo 17.1 LGUM"; "El Estado Autonómico tras la Ley de Garantía..", cit., 2015, pág. 111. En la misma línea I. URRUTIA LIBARONA, señala la «limitación respecto a la capacidad de intervención de las CCAA» (y no del Estado en cuanto que podrá modificar el régimen por él previsto); cit., pág. 214. También J. SOLANES MULLOR considera que el viraje del legislador español, en relación con el principio de unidad de mercado, «no tiene efectos neutrales, tiene un perdedor: la capacidad reguladora de los entes territoriales subestatales»; cit., pág. 116.

${ }_{61}$ Como ya se dijo, la Disposición final segunda de la LGUM modifica el artículo 5 de la Ley Paraguas para ajustarla a estas restricciones, así como la Ley 27/2013, de 27 de diciembre, de Racionalización y sostenibilidad de la Administración Local, modifica la redacción del artículo 84 bis de la Ley de Bases de Régimen Local en el mismo sentido, al que se añade la restricción de RIIG relativas a la autorización de infraestructuras o instalaciones que se mencionan a continuación, en el mismo empeño normalizador.

62 REBOLLO PUIG, M., "El Estado Autonómico tras la Ley de Garantía..", cit., 2015, pág. 115. No desaprovecha este autor la ocasión para calificar de «fenómeno casi paranormal» a "este singular fenómeno de remisión del legislador a la jurisprudencia -más aún, de remisión del legislador estatal y para cuestiones de Derecho interno a la jurisprudencia del Tribunal europeo construida con otra base y a otros efectos-".

${ }_{63}$ El propio REBOLLO, a continuación de lo expuesto, plantea unas interesantes reflexiones sobre lo problemático que resulta la delimitación acertada de la RIIG «orden público», ejemplificándolo con las dudas que suscita su masiva invocación en la Ley andaluza $3 / 2014$, de 1 de octubre, de medidas normativas para reducir las trabas normativas para las empresas, en cuyo anexo aparece como justificación de 65 autorizaciones; además de poner de manifiesto las dudas que suscitan las RIIG justificativas de otras autorizaciones previstas en la misma Ley; "El Estado Autonómico tras la Ley de Garantía..”, cit., 2015, págs. 115-117. 
necesidad y proporcionalidad de la medida en atención a la satisfacción de la concreta razón de interés general en que se fundamente. Lo cual debe contribuir a superar el mero cumplimiento formal de la exigencia de ley para legitimar autorizaciones por medio de meros listados o tablas, a menudo dispuestas en anexos de leyes sin acompañamiento de una mínima justificación.

En definitiva, el legislador español ha optado por fijar un régimen más desregulado del que deriva de las exigencias del mercado interior europeo en la materia ${ }^{64}$. Dicha situación ya se produjo con la normativa de transposición de la Directiva de Servicios, al disponer un numerus clausus de RIIG, no exigido por aquella. Pero, posteriormente, la LGUM la ha sobrepasado, al establecer un nuevo numerus clausus de RIIG para la justificación de autorizaciones extremadamente reducido. La LGUM consolida así un régimen excesivamente restrictivo en relación con la utilización del instrumento autorizatorio por parte de las CCAA que, en ocasiones, podría dejar desasistidos otros intereses públicos no cubiertos por los RIIG acotados, pero igualmente dignos de protección. De esta manera, cuando el legislador autonómico aprecie la necesidad de ejercer algún tipo de control sobre determinadas actividades económicas y no pueda justificar concretamente alguna de las RIIG mencionadas, tendrá que recurrir a su instrumentación a través de declaraciones responsables o comunicaciones, como se comenta a continuación.

\section{B) Declaraciones responsables}

En este sentido, la LGUM (art. 17.2 en combinación con la remisión contenida en el 5.1) admite la exigencia de declaración responsable, tanto para el acceso y ejercicio de la actividad como para las infraestructuras e instalaciones físicas en las que se vaya a desarrollar, cuando se justifique en alguna de las RIIG enumeradas en el artículo 3.1 de la Ley Paraguas: el orden público, la seguridad pública, la protección civil, la salud pública, la preservación del equilibrio financiero del régimen de Seguridad Social, la protección de los derechos, la seguridad y la salud de los consumidores, de los destinatarios de servicios y de los trabajadores, las exigencias de la buena fe en las transacciones comerciales, la lucha contra el fraude, la protección del medio ambiente y del entorno urbano, la sanidad animal, la propiedad intelectual e industrial, la conservación del patrimonio histórico y artístico nacional y los objetivos de la política social y cultural.

Ello supone que, aunque con un margen más amplio, los posibles límites al ejercicio de la libertad de empresa instrumentados a través de declaración responsable, sólo podrán sustentarse en un numerus clausus de razones imperiosas de interés general lo que, de nuevo y como acertadamente ha notado REBOLLO PUIG, deja fuera otras posibles razones que pudieran justificar restricciones a dicha libertad ${ }^{65}$, además de utilizar de forma limitativa una técnica que en el Derecho comunitario, de donde proviene, es abierta y no restringida a una lista cerrada.

\section{C) Comunicaciones}

En cuanto a las comunicaciones, se admiten por las mismas RIIG que las declaraciones responsables, que se acaban de enumerar. No obstante, el artículo 17.3 añade que las autoridades podrán exigirlas cuando «precisen conocer el número de operadores económicos, las instalaciones o las infraestructuras físicas en el mercado». Coincidimos con PERNAS GARCÍA en que la normativa administrativa sectorial muestra que la comunicación transciende normalmente el mero conocimiento estadístico, constituyendo «un instrumento que permite conocer las características de la actividad o instalación, verificar el nivel de cumplimiento de la legislación sectorial, así como ejercer de forma efectiva el control a posteriori de la actividad» ${ }^{66}$.

Por último, el apartado 4 del artículo 17 requiere de las autoridades competentes que, una vez aplicado el principio de necesidad y proporcionalidad, dispongan un único medio de intervención, bien sea una autorización, una declaración responsable o una comunicación. De esta forma se establece la regla de un solo instrumento de intervención: elegido uno, deben excluirse los demás.

${ }^{64}$ En este sentido se ha manifestado I. URRUTIA LIBARONA, cit., pág. 217 y también M. REBOLLO PUIG, "La libertad de empresa tras la Ley...", cit., pág. 29.

65 M. REBOLLO PUIG menciona, entre otras, aquellas contenidas en el artículo 38 de la Constitución, como son las derivadas de la «defensa de la productividad», de las «exigencias de la economía general» o de la «planificación» y añade que la Unión Europea nunca ha considerado que sólo las razones imperiosas de interés general pueden justificar restricciones a la libertad de empresa; "La libertad de empresa", cit., 2014, págs. 26 y 27.

66 J. J. PERNAS GARCÍA, cit., pág. 91. 
Dicha regla es una expresión más del principio finalista de simplificación de cargas recogido en el artículo 7 de la LGUM, tendente a evitar duplicidades innecesarias. La reducción de cargas administrativas, en los supuestos en que se pruebe justificado, en cuanto suponga una simplificación de las actividades de las Administraciones públicas incrementando su eficacia, puede suponer una reducción de costes para estas y también para los agentes económicos.

\section{La disposición de condiciones materiales relativas al ejercicio de la actividad}

Las disposiciones reguladoras de muchas actividades económicas ${ }^{67}$-en buena medida autonómicas-, tienden a establecer una ordenación bastante completa de las mismas incluyendo: a) condiciones y requisitos vinculados al establecimiento físico donde se va a desarrollar la actividad ${ }^{68}$, si ese es el caso; b) requisitos relativos a elementos subjetivos concernientes al operador (constitución formal de la empresa), condiciones relativas a sus gestores o personal (cualificación profesional) o garantías (seguros, fianzas), o similares; c) otros requisitos, deberes, limitaciones o prohibiciones vinculados al funcionamiento y la gestión ordinaria de la actividad una vez iniciada, tales como la existencia de hojas de reclamaciones en los establecimientos, exigencias informativas hacia los consumidores y usuarios, condiciones de comercialización de productos 0 servicios, condiciones de conservación de los productos para su venta, y otras semejantes.

Esta regulación material de la actividad suele ir acompañada de la regulación instrumental del medio de intervención dispuesto para la supervisión de inicio -en la expresión tradicional- o acceso -en la terminología post-Directiva de Servicios- de la actividad.

Este esquema regulatorio, en el que se entremezcla la reglamentación de requisitos relativos a elementos reales, personales o funcionales, tiene sentido por razones sistemáticas y de eficacia normativa. Se pretende con ello plasmar y conformar en un único texto el entero régimen jurídico de una determinada actividad económica, desde los requisitos de acceso a la disciplina de su ejercicio.

Obsérvese que los requisitos incluidos en la letra a) anterior se refieren a elementos por así decirlo estáticos (infraestructuras o instalaciones), mientras que los recogidos en la letra b) presentan una exigencia de permanencia temporal. Es por ello que las normas suelen disponer el deber de mantenimiento en el tiempo de dichos requisitos. Y también es por ello por lo que la garantía del cumplimiento de este tipo de condiciones materiales se suele anudar a la exigencia de alguno de los medios de intervención examinados anteriormente, singularmente una autorización o una declaración responsable al inicio de la actividad, sin perjuicio del eventual control posterior de que se mantiene su cumplimiento por parte de la autoridad de supervisión.

Por contraste, los requisitos recogidos en la letra c), en tanto trabados a la dinámica de la gestión empresarial una vez en marcha, tienen un punto de fugacidad a la que no se acomoda su supervisión por los medios anteriores, sino a través de la inspección.

Las autoridades autonómicas ${ }^{69}$, en el ejercicio de sus potestades de ordenación, pueden naturalmente establecer requisitos relativos al ejercicio de la actividad económica ${ }^{70}$, cuya supervisión debe ser simultánea

\footnotetext{
67 Frecuentemente reglamentarias, en desarrollo de una habilitación legal.

68 Con frecuencia recurriendo en esto a remisiones al cumplimiento de normativa bajo supervisión de las entidades locales, típicamente a las disposiciones vigentes en materia de medio ambiente, edificación, ordenación territorial y urbanística, sanidad e higiene, seguridad, sistemas de prevención, protección, extinción y evacuación en caso de incendios, así como las referidas a la accesibilidad.

69 Ya actúen como autoridades de destino o de origen. Estas últimas, como autoridades competentes para disponer la ordenación y supervisar el ejercicio de la actividad desarrollada por el operador en el mismo territorio donde accedió a la misma, con independencia de que desarrolle también o no dicha actividad en otros territorios. Así, si el operador accede a la actividad en Galicia y, como será frecuente, posteriormente, la ejerce en dicho territorio -con independencia de que la ejerza también en el de Asturias y Cantabria-, será la autoridad gallega la competente para la supervisión y control del ejercicio de dicha actividad en su ámbito territorial, por más que la definición de autoridad de destino del Anexo LGUM no se limita a decir que esta es la competente en el lugar donde el operador desarrolla el ejercicio de dicha actividad, sino que agrega la circunstancia de que dicho operador esté «legalmente establecido en otro lugar del territorio nacional», lo que supone una laguna técnica (al no determinarse cuál es la autoridad competente para supervisar el ejercicio de la actividad desarrollada por el operador en el mismo territorio donde accedió a la misma), que debe integrarse en el sentido expuesto.

70 La diferenciación entre requisitos de ejercicio de la actividad económica en relación con los de acceso a la misma, ha tenido reflejo desde los primeros informes emitidos por la Secretaría del Consejo para la Unidad de Mercado (SECUM) ante reclamaciones presentadas vía artículo 26 LGUM (v. gr. Informe "Juego. Máquinas de apuestas", de 2 de abril de 2014; o Informe "Comercio-Horarios", de 25 de noviembre de 2014), o a través de los denominados «informes de valoración» emitidos en el marco de los procedimientos de información previstos en el artículo 28 de la LGUM (v. gr. Informes "Sanidad-Carteles prohibido fumar", de 29 de octubre de 2014 y "Seguros-Hojas de reclamaciones", de 4 de noviembre de 2014); informes disponibles en la web de la SECUM. A veces, no obstante, como ha notado ALONSO MAS, M. J., "La eficacia de los títulos habilitantes..", cit., pág. 347, puede que «no resulte sencillo determinar
} 
REALA. Nueva Época - N. ${ }^{11}$, Abril-Septiembre 2019 - ISSN: 1989-8975 - DOI: 10.24965/reala.v0i11.10632 - [Págs. 29-55]

Ordenación de las actividades económicas tras las sentencias del Tribunal Constitucional sobre la Ley de Unidad de Mercado

Javier Sola Teyssiere

a dicho ejercicio además de in situ. El operador queda sometido en este aspecto a la normativa vigente en el territorio donde ejerza su actividad económica, sea a través de un establecimiento o sin él, cuya supervisión corresponde a la autoridad competente en dicho territorio.

En todo caso, en el establecimiento de requisitos atinentes al ejercicio de las actividades económicas las autoridades competentes se ven también sometidas a limitaciones ${ }^{71}$.

Por un lado, conforme al dictado expreso del artículo 5.1 de la LGUM $^{72}$, deben motivar su necesidad en el mismo numerus clausus de razones imperiosas de interés general previsto para las declaraciones responsables y comunicaciones que, como se ha visto, están enumeradas en el artículo 3.11 de la Ley Paraguas.

Por otro lado, dichas normas no deben establecer requisitos considerados contrarios a la LGUM en los apartados no anulados del artículo 18.2, como aquellos que pudieran tener efectos discriminatorios, por razón de establecimiento o residencia del operador, o requisitos de seguros de responsabilidad civil o garantías equivalentes o comparables a las exigidas en origen, entre otros, que examinaremos en el epígrafe siguiente.

EI TC destaca el papel que pueden jugar las regulaciones de condiciones materiales de las actividades económicas frente al carácter restrictivo de las autorizaciones. Así en la STC 111/2017, apoyándose en su propia jurisprudencia reiterada a lo largo del mismo año 2017, argumenta que aunque la LGUM «limita los bienes o valores que pueden ser objeto de protección mediante la técnica autorizatoria, al establecer el catálogo taxativo de razones que pueden justificar el control preventivo», ello no pone en riesgo la dimensión social que desarrolla el capítulo III del título I de la Constitución «en la medida en que la Ley 20/2013 no impide que las autoridades competentes "establezcan, respecto de la actividad de que se trate, condiciones materiales destinadas a objetivos legítimos distintos" de los enumerados taxativamente». Al respecto recuerda el Tribunal que «así lo ha razonado la STC 101/2017, de 20 de julio, FJ 10, haciendo referencia específicamente a las Comunidades Autónomas: aunque no puedan tutelar esos otros bienes mediante la exigencia de autorizaciones, sí pueden hacerlo "fijando requisitos y límites y, en general, mediante las regulaciones materiales cuya aprobación le corresponde por virtud de sus Estatutos de Autonomía" (en el mismo sentido: SSTC 79/2017, FJ 7, y 91/2017, de 6 de julio, FJ 7)» ${ }^{73}$.

Es más, el alto Tribunal parece apuntar a la regulación de condiciones materiales como una vía que admitiría mayor flexibilidad en cuanto a la justificación de restricciones. Así, en la misma STC 111/2017 (FJ 4,a), tras recordar que la libertad reconocida en el artículo 38 de la Constitución es compatible con la regulación de condiciones a la misma, señala que dichas condiciones «deben ajustarse a un canon de razonabilidad en el sentido de que respondan a un objetivo constitucionalmente legítimo y sean idóneas o adecuadas para conseguirlo sin que su intensidad llegue al punto de suponer un impedimento práctico del libre ejercicio de la actividad económica». Matizando a continuación que «el canon ha de ser más incisivo si los requisitos o condiciones a la libertad de empresa afectan, no ya a su desarrollo o ejercicio, sino al acceso mismo al mercado (SSTC 53/2014, de 10 de abril, FJ 7; 30/2016, de 18 de febrero, FJ 6, 35/2016, de 3 de marzo, FJ 4 y 89/2017, de 4 de julio, FJ 14)» ${ }^{74}$. De lo que, a sensu contrario, cabe inferir la disposición del Tribunal

cuándo estamos ante una cuestión atinente al ejercicio de la actividad, y competencia de la autoridad de destino; y cuándo estamos ante un requisito relativo al acceso a la misma o a la fabricación o requisitos del producto».

71 M. REBOLLO PUIG ha resaltado la limitación de las posibilidades de imposición de condiciones materiales al ejercicio de las actividades económicas como uno de los aspectos más sustancialmente restrictivos de entre los dispuestos por la LGUM. Para este autor, constituye «el aspecto más importante, el capital, el de más calado, el que restringe más sustancial y severamente las competencias de los distintos poderes públicos y el que, quizás, debilita más sus posibilidades de tutelar aquéllos que consideren intereses generales»; "El Estado Autonómico tras la Ley de Garantía..”, cit., 2015, pág. 101. También M. RODRÍGUEZ PORTUGUÉS, ha destacado el salto cualitativo que suponen las exigencias de la LGUM relativas a los requisitos materiales o sustantivos, frente a las exigencias previas derivadas de la Directiva de Servicios y de la Ley Paraguas, centradas fundamentalmente en requisitos formales o de procedimiento; "El impacto de la Ley de Garantía de la Unidad de Mercado sobre la ordenación del comercio interior", en ob. col. El nuevo marco jurídico de la unidad de mercado. Comentario a la Ley de garantía de la unidad de mercado, Dir. M. J. Alonso Mas, Madrid, 2014, págs. 542-544.

72 Que establece: «Las autoridades competentes que en el ejercicio de sus respectivas competencias establezcan límites al acceso a una actividad económica o su ejercicio de conformidad con lo previsto en el artículo 17 de esta Ley o exijan el cumplimiento de requisitos para el desarrollo de una actividad, motivarán su necesidad en la salvaguarda de alguna razón imperiosa de interés general de entre las comprendidas en el artículo 3.11 de la Ley 17/2009, de 23 de noviembre, sobre el libre acceso a las actividades de servicios y su ejercicio.».

73 FJ 4, b de la STC 111/2017, de 5 de octubre.

74 En la citada STC 35/2016 el Tribunal señala que el «test de proporcionalidad se ha aplicado solamente a regulaciones que pueden afectar al acceso al mercado, al comienzo en el ejercicio de la actividad [...]. Pero cuando se trata de regulaciones que "afectan al ejercicio de una actividad empresarial, sin afectar al propio acceso a la misma", como ocurre en este caso, el canon de constitu- 
a consentir un test de necesidad y proporcionalidad más laxo en relación con la justificación de requisitos materiales atinentes al ejercicio de la actividad.

Cabe especular que, dadas las limitaciones para disponer algunos instrumentos de control ex ante, las autoridades autonómicas, y las locales en la medida de sus posibilidades, opten por centrarse en la introducción de condiciones materiales al ejercicio en la regulación de las actividades económicas bajo su competencia, reforzando los mecanismos de control ex post ${ }^{75}$.

Finalmente, interesa señalar que la LGUM tampoco ha garantizado la eliminación de distorsiones en lo referente a los requisitos de ejercicio de las actividades económicas. Esto es, no contiene medidas que fuercen a las CCAA a equiparar los requisitos que condicionan el funcionamiento de las empresas una vez que han accedido a la actividad. Para la eliminación de distorsiones en este punto habría que apelar a las actuaciones de cooperación tendentes a promover la armonización de las normativas autonómicas previstas en la LGUM, así como a su instrumentación a través de títulos estatales (art. 149.1.13. ${ }^{a}$ y leyes de armonización), ya aludidas anteriormente ${ }^{76}$.

\section{Actuaciones calificadas como limitaciones no admitidas}

Para el aseguramiento del sistema de constricción de las posibilidades interventoras que se viene examinando, el artículo 18.2 de la LGUM define, finalmente, una serie de actuaciones de las autoridades competentes consideradas expresamente como limitaciones a la libertad de empresa no conformes con la Ley, referidas tanto a actuaciones de ordenación normativa como a actuaciones administrativas singulares.

Tras la anulación de las letras b), c) y e) del apartado 2 del artículo 18 por la STC 79/2017, por su vinculación directa con el principio de eficacia como ya se ha visto, la lista de limitaciones prohibidas se ha reducido a las que se comentan a continuación.

En primer lugar, se consideran contrarias a la Ley una serie de actuaciones que presentan un sesgo discriminatorio, y que suponen una pormenorización del principio de no discriminación establecido en el artículo 3 de la propia Ley ${ }^{77}$.

De esta forma, en virtud de la letra a) del apartado 2, se prohíbe la introducción de requisitos discriminatorios «basados directa o indirectamente en el lugar de residencia o establecimiento del operador», para el acceso o ejercicio de una actividad económica, para la obtención de ventajas económicas o para la adjudicación de contratos públicos.

En concreto, se considera ex lege discriminatorio, que la autoridad que disponga alguna de las anteriores medidas establezca requisitos vinculados a su territorio, como que:

1. El operador esté establecido, o tenga su domicilio social, o disponga de un establecimiento físico dentro de aquel.

\footnotetext{
cionalidad empleado por la jurisprudencia de este Tribunal es algo diferente, pues solamente permite verificar si esas medidas son "constitucionalmente adecuadas», esto es, si la medida cuestionada "constituye una medida adecuada para la consecución de un fin constitucionalmente legítimo, sin que le corresponda a este Tribunal ir más allá, pues ello supondría fiscalizar la oportunidad de una concreta elección del legislador, de una legítima opción política» (STC 53/2014, de 10 de abril, FJ 7).

75 Ello puede parecer plausible especialmente en aquellas situaciones en las que la Administración ejerce su labor de supervisión de la legislación protectora de los consumidores, aunque fuera por el rédito político que pudiera teóricamente reportar. Se han indicado variadas motivaciones que pudieran haber incitado a los poderes regionales a generar la tan denostada inflación normativa, no pareciendo siempre justificadas en la protección de intereses realmente diferenciados. Incluso abundan las críticas señalando a motivaciones más o menos espurias o demagógicas, como la justificación de su gestión frente a los gastos que generan a los ciudadanos (BECKER ZUAZUA, F., “¿Qué hacemos con la regulación?”), el efecto imitación entre CCAA, o la tendencia a la diferenciación, introduciendo notas distintivas que la diferencien del resto (GUTIÉRREZ CARRIZO, I., "Marco regulatorio y unidad de mercado: una perspectiva desde el análisis económico"; trabajos ambos incluidos en la ob. col. Marco regulatorio y unidad de mercado, Ed. Círculo de Empresarios, Madrid, 2006, pág. 58 y págs. 137-138, respectivamente.

76 Vid. supra ap. II.3 (nota 50) y también, en este sentido, ALONSO MAS, M. J., "La eficacia de los títulos habilitantes..", cit., 2014, págs. 343-344.

77 Que establece: «1. Todos los operadores económicos tendrán los mismos derechos en todo el territorio nacional y con respecto a todas las autoridades competentes, sin discriminación alguna por razón del lugar de residencia o establecimiento. 2. Ninguna disposición de carácter general, actuación administrativa o norma de calidad que se refiera al acceso o al ejercicio de actividades económicas podrá contener condiciones ni requisitos que tengan como efecto directo o indirecto la discriminación por razón de establecimiento o residencia del operador económico». Ante el interés generado por la polémica regulación de otros aspectos de la LGUM, ha pasado más desapercibido entre los comentaristas la atención prestada por la Ley a este principio que conecta con la larga lucha que el TJUE ha venido desplegando contra medidas discriminatorias encubiertas entre Estados miembros, y cuya correcta aplicación, en nuestra opinión, constituiría el remedio a una buena parte de los problemas justificadores de la Ley.
} 
2. El operador haya residido u operado durante un determinado período de tiempo en el mismo.

3. El operador haya estado inscrito en registros de dicho territorio.

4. El personal, los propietarios o los miembros de los órganos de administración, control o gobierno de la empresa operadora residan en dicho territorio o reúnan condiciones que directa o indirectamente discriminen a las personas procedentes de otros lugares del territorio.

5. El operador deba realizar un curso de formación dentro de dicho territorio ${ }^{78}$.

No parece que haya nada que objetar a que las normativas que puedan disponer las autoridades competentes -lo que incumbe principalmente a las CCAA y también a los Ayuntamientos-, que afecten al acceso o al ejercicio de las actividades económicas eviten la inclusión de requisitos como los que se acaban de enumerar.

Tampoco en relación con los requisitos de solvencia o criterios de adjudicación en relación con la licitación de contratos públicos, lo que está en línea con el principio de no discriminación también presente en la normativa y jurisprudencia en materia de contratación pública europea e interna ${ }^{79}$.

Más peliaguda, sin embargo, parece la aceptación tal cual de las mismas limitaciones en relación con los requisitos que puedan disponer las Administraciones públicas «para la obtención de ventajas económicas», expresión que el artículo 18 no delimita, pero que el anulado artículo 20.3,a) de la misma Ley, al utilizar la misma expresión añadía «bien sean subvenciones o beneficios fiscales»; lo que permite inducir que se apunta a actuaciones públicas en el ámbito del fomento. Desde luego, una lectura literal del precepto induce a interpretar que la LGUM estaría prohibiendo, por ejemplo, que una determinada Administración estableciera requisitos vinculados con la exigencia de establecimiento físico, domicilio social, residencia o ejercicio de la actividad del operador en su territorio, a la hora de establecer las bases reguladoras de una línea de subvenciones dirigidas al fomento de la calidad en la prestación de servicios por parte de los operadores.

No obstante, en el Acuerdo de la Comisión Bilateral de Cooperación Administración General del EstadoComunidad Autónoma de Galicia en relación con las discrepancias manifestadas -entre otros- sobre el artículo 18.2.a) de la LGUM, las partes coinciden en interpretar «que su contenido no obsta a que se pueda exigir el ejercicio de una actividad económica en el territorio para la obtención de ventajas económicas vinculadas a políticas de fomento, sin ello implique discriminación por razón de la nacionalidad o domicilio social de la empresa» ${ }^{80}$. Del contenido de este Acuerdo se colige, por tanto, la admisibilidad de exigencia del ejercicio de la actividad económica subvencionada en el territorio de la Administración que conceda una ayuda lo que, por otra parte, es acorde con el ámbito territorial de su competencia.

El criterio del Acuerdo ha sido coherentemente seguido por la Secretaría del Consejo para la Unidad de Mercado (SECUM) en varios de sus informes emitidos ante reclamaciones presentadas vía artículo 26 LGUM. Valga como ejemplo representativo (en cuanto acumula doctrina previa anterior) el Informe de 24 de agosto de $2016^{81}$ sobre una convocatoria de subvenciones en Cataluña que afecta a centros de formación de empleo en el que, tras invocar expresamente el indicado Acuerdo, se argumenta que la propia naturaleza de la política de fomento exige una cierta territorialidad de sus efectos, por lo que es exigible que las actividades a desarrollar por los operadores solicitantes tengan conexión con el ámbito territorial de la entidad concedente de las subvenciones materializándose, por ejemplo, en la generación de actividad económica

78 Requisito limitado, por tanto, a operadores que sean personas físicas. Llama la atención que no se haya extendido al personal de la empresa, como en el supuesto anterior.

79 Sin perjuicio de que el TJUE haya admitido el requisito de establecimiento en el territorio de la licitadora como condición de ejecución (pero no en fase de adjudicación, que es la expresión que usa la LGUM) como apunta P. A. BOIX MAÑO, con cita de la Sentencia Contse de 27 de octubre de 2005; en "Contratación del sector público", en ob. col. El nuevo marco jurídico de la unidad de mercado. Comentario a la Ley de garantía de la unidad de mercado, dir. M. J. Alonso Mas, Madrid, 2014, pág. 482. Vid. el análisis del principio de no discriminación por razón del establecimiento o la residencia del operador en la contratación pública, puesto en relación con la LGUM, que realiza esta autora en las págs. 472-492 del trabajo citado. El Informe de la SECUM «Contratación pública - equipos protección de bomberos Sevilla, de 2 de octubre de 2017, en relación con el requisito de solvencia de disponibilidad de un centro de trabajo en la provincia de Sevilla, para garantizar la rapidez de las reparaciones de los equipos en los servicios de emergencia, considera que «podrían valorarse otras opciones menos distorsionadoras de la actividad económica como la determinación de un compromiso de tiempo máximo de respuesta». Además, continúa, «en la medida en que el requisito de disponer de establecimiento físico en la provincia de Sevilla pudiera suponer una discriminación por razón del lugar de residencia o establecimiento del operador, ese requisito podría ser contrario al artículo 18.2.a).1. ${ }^{\circ} »$

80 Acuerdo publicado por la Resolución de 14 de octubre de 2014, de la Secretaría General de Coordinación Autonómica y Local (BOE de 29 octubre de 2014).

81 Informe "Centros de Formación de Empleo-Cataluña", de 24 de agosto de 2016. Todos los informes de la SECUM están disponibles en su web: http://www.mineco.gob.es/portal/site/mineco/gum. 
en el mismo. En el caso concreto, considera la Secretaría que puede deducirse la vinculación de la medida cuestionada «con una política de fomento de la actividad económica y de la generación de empleo en el ámbito territorial de la Comunidad Autónoma de Cataluña, políticas sobre las cuales las conexiones territoriales se consideran compatibles con la LGUM».

En base a lo expuesto, cabría inferir una cierta voluntad de la Administración General del Estado de suavizar la aplicación literal de la Ley, admitiendo que las Administraciones autonómicas y locales exijan que las empresas desarrollen su actividad en su territorio al arbitrar ayudas económicas, porque la finalidad es el fomento de la actividad económica en el mismo.

Sin embargo, de nuevo hay señalar los estrechos límites dentro de los que se mueve dicha pretendida relajación pues, en otro Informe de la SECUM también relacionado con una Orden de convocatoria de subvenciones públicas destinadas a la financiación de planes de formación de empleo en Aragón, se considera discriminatorio y contrario al artículo 18.2.a) LGUM el requisito contenido en la convocatoria de disponer de centros o entidades de formación domiciliadas en el territorio de Aragón ${ }^{82}$.

Sobre este asunto, posteriormente, la Comisión Nacional de los Mercados y la Competencia interpuso recurso contencioso-administrativo contra la Orden de convocatoria aludida vía artículo 27 de la LGUM. Lo que llevó a la Audiencia Nacional, por su parte, a plantear una cuestión de inconstitucionalidad en relación con el artículo 18.2.a).1. ${ }^{\circ}$ de la LGUM y, en concreto, respecto al inciso «o que disponga de un establecimiento físico dentro de su territorio», por entender que pudiera invadir la competencia autonómica de ejecución de la legislación estatal en materia laboral. En su reciente Sentencia 121/2018, de 31 de octubre, el Tribunal Constitucional, partiendo de la base de que el precepto cuestionado se ampara en el título competencial estatal del artículo 149.1.13 CE, confirma la validez de este título transversal para condicionar el ejercicio de competencias sectoriales autonómicas, más si cabe, como en el caso, cuando dichas competencias sean ejecutivas, por lo que confirma la constitucionalidad del precepto objetado, desestimando la cuestión planteada. Por cierto, que en contra del criterio del Ministerio Fiscal, que considera que el precepto es inconstitucional ${ }^{83}$.

Ante todo lo expuesto, no puede dejar de señalarse y criticarse la complejidad y las dificultades de interpretación a la que se ven abocados los aplicadores de la LGUM, que parece que están obligados a distinguir entre vinculación del ejercicio de la actividad al territorio y la domiciliación o el establecimiento físico donde frecuentemente aquella habrá de desarrollarse. Lo cual resulta forzado ante la literalidad de la Ley y, en todo caso, no siempre será fácil de dilucidar. Efectivamente, si se admite la primera de dichas vinculaciones, con más razón si cabe, parece admisible la exigencia de implantación territorial en ciertos casos. Especialmente cuando las ayudas estén vinculadas a las infraestructuras o instalaciones físicas fomentando, por ejemplo, la mejora de la calidad de las mismas (piénsese, por ejemplo, en las no infrecuentes ayudas autonómicas dirigidas a la elevación de la calidad o categoría de los establecimientos de alojamiento turístico emplazados en las mismas), pues no tendría sentido que la autoridad convocante fomentara la mejora de las instalaciones radicadas en otro territorio, excediendo la territorialidad de su competencia.

Todo ello evidencia un exceso más de entre los que, como se ha visto, se han achacado a la LGUM, fruto de un cierto extremismo desregulador en el que puntualmente incurre, que, en el caso, se podía haber evitado excepcionando o simplemente matizando sus postulados en relación con las actuaciones de fomento.

Pasando a otros preceptos del artículo 18, el TC ha justificado su rechazo a la declaración de inconstitucionalidad de las letras d) y f) del apartado 2 de dicho artículo, argumentando que los mismos están en la

82 Informe "Educación. Centros de formación de Empleo-Aragón”, de 22 de septiembre de 2015, en reclamación vía artículo 26 contra la Orden de 7 de agosto de 2015, de la Consejería de Economía, Industria y Empleo del Gobierno de Aragón. En el Informe se puede leer: «Si bien, en virtud de la LGUM debe entenderse que esta conexión con el ámbito territorial no puede establecerse exclusivamente en relación a la existencia de un domicilio social o un establecimiento físico concreto (en este supuesto "centros o entidades de formación domiciliadas ...") en un determinado territorio sino, por ejemplo, por la generación de actividad económica en el mismo con base en posibles diferentes indicadores-ventas, empleo generado, prestación de servicios a un determinado tipo de cliente, etc.». Por lo que concluye que «la LGUM considera requisito discriminatorio para la obtención de ventajas económicas la solicitud de establecimiento, establecimiento físico o el domicilio social de operador en el territorio de la autoridad competente. No obstante, la obtención de ventajas económicas vinculadas a las políticas de fomento puede venir vinculada a la solicitud del ejercicio de la actividad económica en un determinado territorio».

83 La Fiscalía General del Estado en sus alegaciones considera que «el precepto resulta desproporcionado y no justificado por su finalidad, al no admitir corrección alguna la prohibición de que la comunidad autónoma pueda exigir o ponderar la existencia de establecimientos físicos en su territorio». Por ello concluye que «la norma cuestionada es inconstitucional por vulnerar la competencia de las Comunidades Autónomas que, en aplicación del principio de territorialidad, pudieran exigir el requisito de contar con establecimiento físico en el territorio. Se infringe el orden de distribución de competencias derivado del artículo 149.1.7 CE y en particular, también del artículo 77.2 del Estatuto de Autonomía de Aragón» (Antecedente 7 in fine de la STC 121/2018). 
línea de evitar conductas públicas discriminatorias y que sus previsiones «no vulneran la libertad de circulación de bienes y personas en todo el territorio nacional (art. 139.2 CE). Antes bien, en opinión del Tribunal la desarrollan, al proscribir condiciones o requisitos concretos por discriminatorios o proteccionistas. Del mismo modo, lejos de dificultar el libre intercambio comercial, lo favorecen, por lo que en modo alguno trasgreden la garantía constitucional de la libertad empresarial (art. 38 CE)» (STC 111/2017, FJ 4,c).

El precepto de la letra d) prohíbe a las autoridades de destino la exigencia a los operadores de requisitos adicionales en relación con los seguros de responsabilidad civil o garantías que ya se les hubieran exigido en origen y que sean equivalentes o comparables a las dispuestas en su propia normativa. Obsérvese que el precepto, en cuanto considera disconforme con la Ley la exigencia de «requisitos de seguros de responsabilidad civil o garantías equivalentes o comparables en lo esencial en cuanto a su finalidad y a la cobertura que ofrezca en términos de riesgo asegurado, suma asegurada o límite de la garantía, adicionales a los establecidos en la normativa del lugar de origen», está admitiendo a sensu contrario que la autoridad de destino pueda exigir una garantía complementaria en dichos supuestos ${ }^{84}$.

El precepto constituye un ejemplo aislado, dentro de la fallida LGUM, de lo que podría haber sido una línea menos radical y más acertada de implantación de un sistema de reconocimiento mutuo que exige, como cautela de seguridad, la habilitación a la autoridad de destino para practicar un test de comprobación de la equivalencia ${ }^{85}$ sustantiva del requisito de acceso del operador en origen con el exigido en su territorio $y$, caso de resultar negativo, poder exigir el complemento necesario de aptitud para garantizar un nivel de protección similar del interés general que sus propios requisitos normativos tratan de preservar, como hemos propuesto en otro lugar ${ }^{86}$. En todo caso, adquiere renovado valor, una vez eliminado el inconveniente que allí señalábamos de que el precepto parecía estar en contradicción interna con el artículo 19.3 de la misma ley ${ }^{87}$, al haber sido anulado este último.

La segunda parte de la letra d) rechaza además una conducta con visos proteccionistas al proscribir que la autoridad competente pueda exigir que las aludidas garantías o seguros deban suscribirse con un prestador radicado en su territorio. Dicha circunstancia se encuentra recogida expresamente en la lista de requisitos prohibidos de la Directiva de Servicios (art. 14.7) y de la Ley Paraguas (art. 10,g).

Resulta discordante con lo que se acaba de comentar, en relación con la comprobación de la equivalencia, la redacción de la letra f) que prohíbe a las autoridades competentes la «exigencia de requisitos de obtención de una autorización, homologación, acreditación, calificación, certificación, cualificación o reconocimiento, de presentación de una declaración responsable o comunicación o de inscripción en algún registro para acreditar la equivalencia de las condiciones que reúne el operador establecido en otro lugar del territorio» con los requisitos exigidos por las autoridades convocantes para la concesión de ventajas económicas. No parece coherente que en el supuesto de la letra d) se acepte la comprobación de la equivalencia y en estos supuestos no.

Reiterados Informes de la SECUM ${ }^{88}$-anteriores a las SSTC de 2017- han considerado contrario al principio de no discriminación, junto al de eficacia, la inclusión en las convocatorias de medidas de fomento

${ }^{84}$ En el mismo sentido ALONSO MAS, M. J., "La eficacia de los títulos habilitantes..”, cit., 2014, pág. 345 (nota 63), que asimismo señala el antecedente que tiene este precepto en el artículo 23 de la Directiva de Servicios.

${ }_{85}$ Se hacen eco del mencionado atributo de equivalencia como premisa para una correcta aplicación del reconocimiento mutuo, entre otros C. PADRÓS REIG y J. M. MACÍAS CASTAÑO, cit., págs. 126-127; T. DE LA QUADRA-SALCEDO FERNÁNDEZ DEL CASTILLO, cit., págs. 228-229; y J. AGUDO GONZÁLEZ, cit., pág. 390. Asimismo, I. URRUTIA LIBARONA, cit., págs. 234-235, crítica que el principio de eficacia se haya construido de forma ajena a estos principios, por lo que propone «articular un verdadero sistema de equivalencia y reconocimiento mutuo entre las autoridades autonómicas competentes».

${ }^{86}$ Vid. J. SOLA TEYSSIERE, "El principio de eficacia nacional..", cit., págs. 243-244. Situación sí prevista en el artículo 21. 2 de la Ley Paraguas: "Cuando un prestador que se establezca en España ya esté cubierto por un seguro de responsabilidad civil profesional u otra garantía equivalente o comparable en lo esencial en cuanto a su finalidad y a la cobertura que ofrezca en términos de riesgo asegurado, suma asegurada o límite de la garantía en otro Estado miembro en el que ya esté establecido, se considerará cumplida la exigencia a la que se refiere el apartado anterior. Si la equivalencia con los requisitos es sólo parcial, podrá exigirse la ampliación del seguro u otra garantía hasta completar las condiciones que se hayan establecido en la norma que lo regula».

${ }_{87}$ Que obligaba a las autoridades de destino a admitir la plena validez de los requisitos, cualificaciones, controles previos 0 garantías obtenidos por el operador al amparo de la normativa del lugar en origen aunque sean distintos y «difieran en su alcance o cuantía» de los propios.

${ }^{88}$ Véase por todos el anteriormente mencionado Informe "Centros de Formación de Empleo-Cataluña", de 24 de agosto de 2016 (y las citas que el mismo contiene a Informes anteriores), en el que se concluye que «el requisito de inscripción o acreditación en el Registro de centros y entidades de formación del Servicio de Empleo de Cataluña, exigido a las entidades formadoras externas que sean contratadas por los beneficiarios de la convocatoria [...] resulta contrario a los principios de no discriminación y eficacia nacional de los artículos 18 y 20 de la Ley 20/2013, de 9 de diciembre, de garantía de la unidad de mercado». 
del requisito de inscripción de la empresa solicitante en un registro competencia de la administración convocante. Compartimos la opinión de que dicha exigencia es excesiva, pero no lo sería la habilitación de la facultad de la Administración convocante de comprobar la equivalencia de los requisitos aportados por la empresa externa con los exigidos a sus propios operadores; que podría llevarse a cabo, en su caso, a través de actuaciones de cooperación.

En todo caso, no se entiende bien que el TC haya anulado las letras b), c) y e) del artículo 18.2, por su conexión con el principio de eficacia, y no haya anulado esta letra f), cuando su vinculación con dicho anulado principio es también evidente ${ }^{89}$. De hecho los Informes de la SECUM que se acaban de aludir, recurren al argumento -basado en el ahora anulado art.20- de que «las acreditaciones o inscripciones en registros tienen validez nacional, por lo que no cabe solicitar un registro específico en un determinado ámbito territorial concreto para la obtención de ventajas económicas» ${ }^{90}$.

Por otra parte, la letra g) del artículo 18.2 prohíbe que las autoridades competentes introduzcan «requisitos de naturaleza económica o intervención directa o indirecta de competidores en la concesión de autorizaciones, en los términos establecidos en las letras e) y f) del artículo 10 de la Ley 17/2009, de 23 de noviembre, sobre libre acceso a las actividades de servicios y su ejercicio». Se trata de conductas desde hace mucho tiempo rechazadas por la jurisprudencia del TJUE, que encuentran su expresión concreta en forma de prohibiciones en la Directiva de Servicios (art. 14). La LGUM se limita aquí a remitir a la redacción mucho más pormenorizada ${ }^{91}$ de estos requisitos prohibidos en relación con las autorizaciones contenida en la Ley Paraguas; con el efecto, eso sí, de extender la prohibición a todas las actividades económicas, conforme al ámbito de aplicación de la LGUM.

En el grupo de limitaciones tendentes a evitar actuaciones discriminatorias hay que incluir también la previsión de la letra h) del mismo apartado y artículo, prohibiendo que en cualquiera de las actuaciones públicas descritas se incorporen requisitos que supongan la exigencia para el operador de haber realizado inversiones en el territorio de la Administración actuante.

Finalmente, la lista se cierra con una cláusula amplia en la que genéricamente se veta «cualquier otro requisito que no guarde relación directa con el objeto de la actividad económica o con su ejercicio» ${ }^{92}$, que, en cuanto demanda un elemento de coherencia de las medidas, presenta una vinculación con el cumplimiento del principio de necesidad.

\section{EXTRACTO Y CONCLUSIONES}

1. La LGUM constituye el último episodio significativo de una estrategia legislativa desreguladora que, en dicha Ley, se asienta sobre dos puntales básicos. Por un lado, el principio de eficacia en todo el territorio nacional de los medios de intervención administrativa sobre el acceso a las actividades económicas. Por otro, el sistema de limitación de los medios de intervención administrativa sobre las actividades económicas.

2. La anulación de la regulación del primero de dichos principios por el TC debilita aquella estrategia en

\footnotetext{
89 Vinculación que también señala ALONSO MAS, M. J., "Garantías sustantivas de los operadores económicos: requisitos y límites de la actuación de las "autoridades competentes»", en ob. col. El nuevo marco jurídico de la unidad de mercado. Comentario a la Ley de garantía de la unidad de mercado, dir. M. J. Alonso Mas, Madrid, 2014, pág. 207.

90 Vid. Informe "Educación - Centros Formación Empleo Asturias", de 19 de febrero de 2016, y la remisión que en el mismo se hace a otros Informes anteriores en los que se recoge la misma conclusión.

91 Artículo 10 Ley Paraguas: «e) Requisitos de naturaleza económica que supediten la concesión de la autorización a la prueba de la existencia de una necesidad económica o de una demanda en el mercado, a que se evalúen los efectos económicos, posibles o reales, de la actividad o a que se haga una apreciación de si la actividad se ajusta a los objetivos de programación económica fijados por la autoridad competente o a que se comercialicen productos o servicios de un tipo o procedencia determinada. Las razones imperiosas de interés general que se invoquen no podrán encubrir requisitos de planificación económica. f) Intervención directa o indirecta de competidores, incluso dentro de órganos consultivos, en la concesión de autorizaciones o en la adopción de otras decisiones de las autoridades competentes relativas al establecimiento para el ejercicio de una actividad de servicios, sin perjuicio de la actuación de colegios profesionales y consejos generales y autonómicos de colegios profesionales, como autoridades competentes, en el ámbito de las competencias que les otorga la Ley. Esta prohibición se extiende a organismos como las cámaras de comercio y a los interlocutores sociales en lo que concierne al otorgamiento de autorizaciones individuales, pero esa prohibición no afectará a la consulta de organismos como las cámaras de comercio o de los interlocutores sociales sobre asuntos distintos a las solicitudes de autorización individuales, ni a una consulta del público en general».

92 Para M. J. ALONSO MAS se trata de una «cláusula residual, que corrobora que lo indicado en el art. 18-2 constituye un listado abierto»; "Garantías sustantivas de los operadores..", cit., pág. 211.
} 
REALA. Nueva Época - N. ${ }^{0}$ 11, Abril-Septiembre 2019 - ISSN: 1989-8975 - DOI: 10.24965/reala.v0i11.10632 - [Págs. 29-55]

Ordenación de las actividades económicas tras las sentencias del Tribunal Constitucional sobre la Ley de Unidad de Mercado

Javier Sola Teyssiere

la medida en que pueda reactivar la exigencia de requisitos de acceso a operadores -ajenos al sector servicios- por parte de las autoridades de destino, al haberse desactivado parcialmente la obligación de reconocimiento del título habilitante de origen y, con ello, una de las medidas que contribuían a la reducción de cargas administrativas para los operadores.

3. A pesar de ello, la LGUM mantiene su fuerza desreguladora, al haber avalado el TC el sistema de limitación de los medios de intervención administrativa sobre las actividades económicas, que constituye el instrumento de más garra en el sostenido empeño desregulador, en cuanto que directamente constriñe la capacidad interventora pública sobre aquellas actividades.

4. Especialmente contribuye a la realización del aludido empeño el régimen fuertemente restrictivo para las posibilidades regulatorias autonómicas y locales sobre control administrativo preventivo de las actividades económicas dispuesto en el artículo 17 de la Ley, a través del que se establece un numerus clausus excesivamente reducido de razones imperiosas de interés general que pueden ser invocadas para establecer autorizaciones.

5. Menos restricciones se presentan en cuanto a las posibilidades de establecer la regulación de condiciones materiales y requisitos relativos al ejercicio de las actividades económicas, no sólo porque el ámbito de posibles justificaciones es más amplio (cualquier RIIG del artículo 3 de la Ley Paraguas), sino también teniendo en cuenta las apreciaciones del TC al respecto, que apuntan en la dirección de flexibilización del control de razonabilidad en este aspecto.

6. Finalmente, se pone de manifiesto la necesidad de hacer una lectura matizada de las actuaciones de las autoridades competentes calificadas expresamente como limitaciones no admitidas por el artículo 18 de la Ley. Especialmente en relación con las medidas de fomento, admitiendo que las Administraciones autonómicas y locales exijan que las empresas desarrollen su actividad en su territorio al arbitrar ayudas económicas cuya finalidad sea el fomento de la actividad económica en el mismo, lo que es acorde con el ámbito territorial de su competencia.

\section{BIBLIOGRAFÍA}

AGUDO GONZÁLEZ, J. (2018): "La extraterritorialidad de las actuaciones jurídico-administrativas de las Comunidades Autónomas", en Revista de Administración Pública, núm. 206. DOI: https://doi.org/10.18042/cepc/rap.206.04.

AGUDO GONZÁLEZ, J. (2015): "La administración del reconocimiento mutuo. Un análisis a partir de la libre circulación de profesionales... hasta la unidad de mercado”, en Revista de Administración Pública, núm. 197. DOI: https://doi.org/10.18042/cepc/rap.197.12.

ALONSO MAS, M. J. (2014): "La eficacia de los títulos habilitantes en todo el territorio nacional y la aplicación de la regla del lugar de origen”, en ALONSO MAS, M. J. (dir.): El nuevo marco jurídico de la unidad de mercado. Comentario a la Ley de garantía de la unidad de mercado. Madrid: La Ley.

ALONSO MAS, M. J. (2014): "Garantías sustantivas de los operadores económicos: requisitos y límites de la actuación de las "autoridades competentes»", en ALONSO MAS, M. J. (dir.): El nuevo marco jurídico de la unidad de mercado. Comentario a la Ley de garantía de la unidad de mercado. Madrid: La Ley.

BECKER ZUAZUA, F. (2006): “¿Qué hacemos con la regulación?”, en Marco regulatorio y unidad de mercado. Madrid: Círculo de Empresarios.

BOIX MAÑO, P. A. (2014): “Contratación del sector público", en ALONSO MAS, M. J. (dir.): El nuevo marco jurídico de la unidad de mercado. Comentario a la Ley de garantía de la unidad de mercado. Madrid: La Ley.

CANALS I AMETLLER, D. (2014): "Reforma de la Administración Pública y unidad de mercado: incidencias en el régimen de intervención municipal en la actividad económica privada", en Cuadernos de Derecho Local, núm. 36.

CARLÓN RUIZ, M. (2014): "Los mecanismos de protección de la unidad de mercado en el seno de la Ley 20/2013", en Revista Española de Derecho Administrativo, núm. 165.

CIDONCHA MARTÍN, A. (2010): "La unidad de mercado como límite constitucional a la descentralización: un balance", en La unidad de mercado en la España actual. Madrid: Instituto de Estudios Económicos.

DE LA QUADRA-SALCEDO FERNÁNDEZ DEL CASTILLO, T. (2010): "Libertad de establecimiento y de servicios: ¿Reconocimiento mutuo o país de origen?”, en Revista Española de Derecho Administrativo, núm. 146.

DE LA TORRE MARTÍNEZ, L. (2016): "Los principios de proporcionalidad y de necesidad bajo el prisma de la garantía de la unidad de mercado: ¿nuevos condicionantes de las ordenanzas locales de telecomunicaciones?”, en Revista Española de Derecho Administrativo, núm. 181, págs. 191-225.

FERNÁNDEZ FARRERES, G. (2014): "Unidad de mercado y libertades de empresa y de circulación en la Ley 20/2013, de 9 de diciembre”, en Revista Española de Derecho Administrativo, núm. 163.

FERNANDO PABLO, M. (2011): "Unidad de mercado, discriminaciones inversas y el papel del Tribunal Constitucional”, en Noticias de la Unión Europea, núm. 317. 
REALA. Nueva Época - N. ${ }^{11}$, Abril-Septiembre 2019 - ISSN: 1989-8975 - DOI: 10.24965/reala.v0i11.10632 - [Págs. 29-55]

Ordenación de las actividades económicas tras las sentencias del Tribunal Constitucional sobre la Ley de Unidad de Mercado

Javier Sola Teyssiere

FERNANDO PABLO, M. (1992): "Las funciones del principio de unidad de mercado en la jurisprudencia constitucional", en Revista Española de Derecho Administrativo, núm. 73.

GIFREU FONT, J. (2014): "La impronta de la Directiva de servicios y de la normativa de transposición interna estatal en las técnicas interventoras urbanísticas. Parada y fonda: la Ley de garantía de la unidad de mercado", en Revista Vasca de Administración Pública, núm. 98.

GUILLÉN CARAMÉS, J. (2005): Libre competencia y Estado autonómico. Madrid: Marcial Pons.

GUTIÉRREZ CARRIZO, I. (2006): "Marco regulatorio y unidad de mercado: una perspectiva desde el análisis económico", en Marco regulatorio y unidad de mercado. Madrid: Círculo de Empresarios.

JIMÉNEZ GARCÍA, F. (2007): "Variaciones sobre el principio de reconocimiento mutuo y la Directiva 2006/123/CE en el marco de la libre prestación de servicios", en Revista de Derecho Comunitario Europeo, núm. 28.

LENCE REIJA, C. (2017): "La tutela de la libertad de empresa frente a intervenciones administrativas desproporcionadas", en Revista General de Derecho Administrativo, núm. 46.

LEÓN SANZ, J. (2013): "La garantía de la unidad de mercado", en Revista Información Comercial Española, núm. 871.

LOZANO CUTANDA, B. (2014): "Ley 20/2013, de Garantía de la Unidad de Mercado: las diez reformas clave”, en Revista CESCO de Derecho de Consumo, núm. 9.

MARCOS, F. (2011): "A vueltas con la «unidad de mercado nacional»", en Working Paper IE Law School, AJ-177.

MUÑOZ MACHADO, S. (2014): "Sobre el restablecimiento legal de la unidad de mercado", en Revista Española de Derecho Administrativo, núm. 163.

NARBÓN FERNÁNDEZ, J. (2014): "El principio de cooperación y confianza mutua en la LGUM", en ALONSO MAS, M. J. (dir.): El nuevo marco jurídico de la unidad de mercado. Comentario a la Ley de garantía de la unidad de mercado. Madrid: La Ley.

NARBÓN FERNÁNDEZ, J. (2016): "Los discutibles presupuestos económicos de la Ley de Garantía de la Unidad de Mercado", en Revista Española de Derecho Administrativo, núm. 175.

PAREJO ALFONSO, L. (2015): "La ordenación de la economía”, en PAREJO ALFONSO, L. (dir.): Lecciones de Derecho Administrativo. Orden económico y sectores de referencia, 6. ${ }^{a}$ ed. Valencia: Tirant lo Blanch.

PADRÓS REIG, C. y MACÍAS CASTAÑO, J. M. (2014): "Los instrumentos administrativos de garantía de la unidad de mercado", en Revista de Administración Pública, núm. 194.

REBOLLO PUIG, M. (2015): "El Estado Autonómico tras la Ley de Garantía de la Unidad de Mercado y sus principios de necesidad y eficacia nacional”, en Revista Andaluza de Administración Pública, núm. 91.

REBOLLO PUIG, M. (2014): “La libertad de empresa tras la Ley de Garantía de la Unidad de Mercado", en Revista Española de Derecho Administrativo, núm. 163.

RODRÍGUEZ PORTUGUÉS, M. (2014): "El impacto de la Ley de Garantía de la Unidad de Mercado sobre la ordenación del comercio interior", en ALONSO MAS, M. J. (dir.): El nuevo marco jurídico de la unidad de mercado. Comentario a la Ley de garantía de la unidad de mercado. Madrid: La Ley.

SANTAMARÍA PASTOR, A. (2014): "El contencioso de la unidad de mercado", en ALONSO MAS, M. J. (dir.): EI nuevo marco jurídico de la unidad de mercado. Comentario a la Ley de garantía de la unidad de mercado. Madrid: La Ley.

SOLA TEYSSIERE, J. (2018): "La existencia de un estándar normativo equivalente como condición de constitucionalidad del anulado principio de eficacia nacional de la Ley de unidad de mercado (STC 79/2017)", en Revista Española de Derecho Administrativo, núm. 189.

SOLA TEYSSIERE, J. (2016): "EI principio de eficacia nacional de los medios de intervención de acceso a las actividades económicas”, en Revista Española de Derecho Administrativo, núm. 179.

SOLA TEYSSIERE, J. (2015): "Unidad de mercado y supervisión administrativa de las actividades económicas", en Revista de Administración Pública, núm. 197. DOI: https://doi.org/10.18042/cepc/rap.197.04.

SOLANES MULLOR, J. (2017): "La desconstitucionalización y europeización del principio de unidad de mercado: el Estado de las Autonomías bajo presión", en Revista Vasca de Administración Pública, núm. 109, vol. II.

TENA PIAZUELO, V. (2006): "Defensa del principio de unidad mercado. Riesgo de fragmentación de los mercados a través de la regulación", en Marco regulatorio y unidad de mercado. Madrid: Círculo de Empresarios.

TORNOS MAS, J. (2014): "La ley 20/2013, de 9 de diciembre, de garantía de la unidad de mercado. En particular, el principio de eficacia", en Revista d'Estudis Autonòmics i Federals, núm. 19.

URRUTIA LIBARONA, I. (2016): "La configuración legal de la unidad de mercado y Estado autonómico", en Revista Española de Derecho Administrativo, núm. 175.

VAQUER CABALLERÍA, M. (2010): La eficacia territorial y temporal de las normas. Valencia: Tirant lo Blanch.

VICENTE RUIZ, M. D. (2013): "La necesaria cooperación administrativa para hacer efectiva la unidad de mercado", en Revista Información Comercial Española, núm. 871. 